NBER WORKING PAPER SERIES

\title{
FINANCIAL FRAGILITY IN THE COVID-19 CRISIS: THE CASE OF INVESTMENT FUNDS IN CORPORATE BOND MARKETS
}

\author{
Antonio Falato \\ Itay Goldstein \\ Ali Hortaçsu \\ Working Paper 27559 \\ http://www.nber.org/papers/w27559 \\ NATIONAL BUREAU OF ECONOMIC RESEARCH \\ 1050 Massachusetts Avenue \\ Cambridge, MA 02138 \\ July 2020, Revised May 2021
}

\begin{abstract}
Views expressed are those of the authors and do not necessarily represent the views of the Board, its staff, or the National Bureau of Economic Research. We thank Jaewon Choi, Valentin Haddad, Yi Li, Nellie Liang, Yiming Ma, Jeremy Stein, Annette Vissing-Jorgensen, Yao Zeng, and participants at the Brookings Webinar on "COVID-19 and the Financial System - How and Why Were Financial Markets Disrupted?", the Princeton-Stanford Conference on "Corporate Finance and the Macroeconomy under COVID-19", the Atlanta Fed Conference on "Financial Stability and the Coronavirus Pandemic," the Annual Meeting of the American Finance Association, the Darden-ICI Symposium on Mutual Funds and ETFs, and the Annual Meeting of the Midwest Finance Association, for helpful comments and discussions. Jacob Faber provided excellent research assistance. All remaining errors are ours.
\end{abstract}

At least one co-author has disclosed additional relationships of potential relevance for this research. Further information is available online at http://www.nber.org/papers/w27559.ack

NBER working papers are circulated for discussion and comment purposes. They have not been peer-reviewed or been subject to the review by the NBER Board of Directors that accompanies official NBER publications.

(C) 2020 by Antonio Falato, Itay Goldstein, and Ali Hortaçsu. All rights reserved. Short sections of text, not to exceed two paragraphs, may be quoted without explicit permission provided that full credit, including $\odot$ notice, is given to the source. 
Financial Fragility in the COVID-19 Crisis: The Case of Investment Funds in Corporate Bond Markets

Antonio Falato, Itay Goldstein, and Ali Hortaçsu

NBER Working Paper No. 27559

July 2020, Revised May 2021

JEL No. G01,G1,G23,G38

\begin{abstract}
In the decade following the financial crisis of 2008, investment funds in corporate bond markets became prominent market players and generated concerns of financial fragility. The COVID-19 crisis provides an opportunity to inspect their resilience in a major stress event. Using daily microdata, we document major outflows in corporate-bond funds during the COVID-19 crisis. Large outflows were sustained over weeks and most severe for funds with illiquid assets, vulnerable to fire sales, and exposed to sectors hurt by the crisis. By providing a liquidity backstop for their bond holdings, the Federal Reserve bond purchase program helped to reverse outflows especially for the most fragile funds. In turn, the program had spillover effects on primary market issuance and peer funds. The evidence points to a "bond-fund fragility channel" whereby the Fed liquidity backstop transmits to the real economy via funds.

Antonio Falato

Federal Reserve Board

Mail Stop \#89

20th Street \& Constitution Ave. NW

Washington, DC 20551

antonio.falato@frb.gov

Itay Goldstein

The Wharton School

University of Pennsylvania

3620 Locust Walk

Philadelphia, PA 19104

and NBER

itayg@wharton.upenn.edu

Ali Hortaçsu

Kenneth C. Griffin Department of Economics

University of Chicago

1126 East 59th Street

Chicago, IL 60637

and NBER

hortacsu@uchicago.edu
\end{abstract}




\section{Introduction}

In the decade following the financial crisis of 2008, investment funds in corporate bond markets became prominent market players and generated concerns of financial fragility. Figure 1 demonstrates the dramatic growth of their assets under management relative the size of the corporatebond market since the 2008-2009 crisis. Part of this growth is attributable to the increased regulation of banks, which led market forces to push some of the activities from banks to other non-bank intermediaries. One of the most prominent concerns that emerged was their fragility. For example, the Financial Stability Board flagged the combination of their illiquid assets and size as one of the key vulnerabilities in its 2017 report. Just in 2019, Mark Carney, the governor of the Bank of England, warned that investment funds that include illiquid assets but allow investors to take out their money whenever they like were "built on a lie" and could pose a big risk to the financial sector. However, despite concerns regarding their fragility, the last decade did not feature major stress events to test the resilience of corporate-bond investment funds. Hence, there is a dearth of systematic evidence on their resilience in large stress events.

Recent events around the COVID-19 crisis provide an opportunity to conduct such an analysis and inspect the resilience of these important non-bank financial intermediaries in a major stress event and the unprecedented policy actions that followed it. The COVID-19 crisis unfolded quickly in the US and around the world in early 2020. Initial declaration of a public health emergency was made in January 31, with reports of confirmed infections intensifying in March. On March 13, a national emergency at the federal level in the US was declared. Financial markets tumbled as these events took place, with corporate bond markets in particular experiencing severe stress amid major liquidity problems. The Federal Reserve responded aggressively with the announcement in March 23 of the Primary Market Corporate Credit Facility (PMCCF) and Secondary Market Corporate Credit Facility (SMCCF), which were designed to purchase $\$ 300 \mathrm{bn}$ of investment-grade corporate bonds. In April 9, the Fed announced the expansion of these pro- 
grams to a total of $\$ 850 \mathrm{bn}$ and an extension of coverage to some high-yield bonds. These facilities were unprecedented in the history of the Fed, as this was the first time the US got into the purchase of corporate bonds. As such, their announcements had a major impact on corporate-bond markets. Spreads for both investment-grade and high-yield rated corporate bonds, which almost tripled relative to their pre-pandemic level by March 23, reversed after the two policy announcements (Appendix Figure A.1).

Our goal in this paper is to provide a systematic empirical analysis of the fragility experienced by these funds during a time of severe market stress and shed light on how the Fed's actions contributed to its resolution. We use daily data on flows into and out of mutual funds in corporate bond markets during this crisis. In comparing these flows to those observed in recent history, we assess the impact that this extreme market stress event had on these market players. Our data enables us to shed light on the determinants of flows across different funds, and so to understand better the sources of fragility of funds and also what ultimately helped mitigate fragility. The data is comprehensive and allows us to shed light also on the fragility of another important class of investment vehicles, ETFs. In summary, we highlight three main sources of fragility, asset illiquidity, vulnerability to fire-sales, and sector exposure. By providing a liquidity backstop for their bond holdings, we show that the Fed bond purchase program helped to mitigate fragility. In turn, the Fed bond purchase program had spillover effects, stimulating primary market bond issuance by firms whose outstanding bonds were held by the impacted funds and stabilizing peer funds whose bond holdings overlapped with those of the impacted funds. This analysis uncovers a novel transmission channel of unconventional monetary policy via non-bank financial institutions, which carries important policy lessons for how the Fed bond purchases transmit to the real economy.

We start by documenting the scale of the stress imposed on investment funds in corporate bond markets during the COVID-19 crisis. Simple charts and statistical analysis show that funds 
experienced outflows that were unprecedented relative to what they have seen over the decade since becoming such prominent players in corporate bond markets. Between the months of February and March the average fund experienced cumulative outflows of about $10 \%$ of net asset value, far larger than the average cumulative outflows of about $2.2 \%$ at the peak of the Taper Tantrum in June-July of 2013, which was the other most stressful episode over the last decade (for an analysis of this episode, see Feroli, Kashyap, Schoenholtz, and Shin, 2014). Other dimensions we look at also point to a bigger and deeper stress experienced during the current crisis. The fraction of funds experiencing extreme outflows and the fraction of those experiencing such outflows over a couple of days or more went up to levels far higher than ever recorded, including during the Taper Tantrum episode. Hence, by all measures the COVID-19 crisis brought investment funds in corporate-bond markets to an uncharted territory in having to deal with massive outflows.

Inspecting the development of flows over the period of the COVID-19 crisis, we split the period into different sub-periods. We consider the month of February as a "build-up" phase, the first half of March (till March 13) as the "outbreak" phase, and the second half of March after the national emergency declaration (till the first Fed policy announcement on March 23) as the "peak" phase. Funds suffered the outflows mostly in the peak phase, where redemption hit a torrid pace. This suggests that investors in these funds did not panic till fairly late in the crisis, when the indications for impact on the US economy were very clear. However, as we will discuss below, looking in the cross section of funds reveals a more subtle message. Both the announcements of Fed policy actions that ensued on March 23 and April 9 were effective at stopping the bleeding and reversing the outflows from corporate-bond funds, but it took the second announcement for outflows to fully reverse.

Going into the sources of fragility, we start by analyzing the effect of the illiquidity of the fund's assets. Chen, Goldstein, and Jiang (2010) and Goldstein, Jiang, and Ng (2017) highlight that fragility may emanate from the liquidity mismatch that funds exhibit when they hold illiquid 
assets but promise their investors high levels of liquidity. This has been shown to create a "run" dynamic across investors encouraging them to withdraw before others, which amplifies withdrawals from mutual funds. We split funds based on the levels of liquidity of their holdings, employing common measures of bond liquidity. Confirming the hypothesis that illiquidity amplifies fragility, illiquid funds suffered much more severe outflows during the COVID-19 crisis than liquid funds. Interestingly, while for the overall fund population withdrawals did not start until the peak of the crisis, for illiquid funds they started well before. This indicates that investors started to panic early in illiquid funds, understanding that run dynamics in play make it important to act before redemptions accelerate. The Fed policy announcement proved particularly effective at stopping the bleeding for illiquid funds, where outflows slowed even more relative to their torrid pace at the peak of the crisis. Finally, ETFs were more resilient in the crisis relative to similarly performing funds, owing arguably to their redemptions being less prone to liquidity mismatch.

We also explore other sources of fragility. Building on recent work by Falato, Hortacsu, Li, and Shin (2019), we split the universe of funds according to a measure of vulnerability, capturing the extent to which they are exposed to fire-sale risk. A fund is more exposed to such risk when it has greater commonality in holdings with other funds and when the assets it holds are more likely to exhibit higher price impact. More vulnerable funds experienced greater outflow pressure during this COVID-19 episode. And, as it was the case for illiquid funds, the Fed announcements differentially benefitted the more vulnerable funds, which experienced a larger drop in outflow pressure after the first policy announcement on March 23. Finally, zooming in on the unique forces at play in the COVID-19 episode, funds holding bonds in affected industries suffered greater outflows and experienced greater reversal of outflows following the Fed announcements. These results further support the idea that the particular forces that were in play during the COVID-19 crisis affected the funds investing in corporate bonds. The results also point to relatively quick stabilization benefits of the Fed announcements, especially among the most fragile funds. 
In the last part of the analysis, we examine in more detail the impact of the policy response over the post-crisis period. Our evidence so far indicates that the two main Fed announcements helped to stop the panic and reverse outflows, and particularly so for more fragile funds. But how sustained was the rebound over the post-crisis months and did the Fed policy actions continue to help over the longer run? Growing evidence points to improved bond market liquidity and functioning post-crisis, largely owing to the new role of the Fed as provider of a liquidity backstop or "market maker of last resort" (see O'Hara and Zhou, 2020, and Gilchrist, Wei, Yue, and Zakrajsek, 2020). We find that between April and August fund flows continued to rebound, posting cumulative inflows of over $9 \%$ relative to their net assets, on average. The Fed actions helped to sustain the rebound. Using information on the SMCCF bond purchase eligibility criteria, ${ }^{1}$ we show that there is a strongly statistically and economically significant positive (negative) relation between fund flows (large outflows) and measures of fund exposure to the Fed facility. Intuitively, these measures rank as having high exposure those funds that hold a high proportion of bonds eligible for purchase by the SMCCF. Interestingly, exposure to the SMCCF benefitted particularly the funds that were fragile, either due to illiquidity or vulnerability to fire-sales. Thus, by improving the liquidity of the bonds held by funds, the Fed liquidity backstop is an effective financial stability tool to reduce fund fragility. As such, it served as an effective substitute for a separate ad-hoc facility to stabilize the bond fund sector, such as the Money Market Mutual Fund Liquidity Facility (MMLF) which was used to stabilize money market funds.

Importantly, as funds impacted by the Fed facility became less fragile over the post-crisis period, they generated positive spillovers to primary bond markets and to other funds that hold similar securities. To examine the transmission of the Fed purchases via funds - i.e., whether fund exposure to the Fed bond purchase facility had a spillover effect on firm access to bond financing in the primary markets, we build on the evidence in Zhu (2020) that funds that hold a firm's

\footnotetext{
${ }^{1}$ The eligibility criteria are: maturity of under 5 years, domiciled in the US, not an insured depository institution, and rated investment grade as of March 22, 2020 and not lower than BB+ afterwards.
} 
existing bonds have a high propensity to acquire additional new issuances from the same firm. We find that firms whose existing bondholders had higher exposure to the Fed facility benefitted from the reduction in their bondholders' fragility both in terms of greater issuance volumes and lower spreads for newly issued bonds. Also, spreads in the secondary markets were lower for these firms. We also find evidence of a second aspect of the transmission of Fed purchases i.e., not just the funds that held bonds that were eligible for purchase by the Fed, but also their peers benefitted, with peer funds defined similar to Falato et al. (2019) based on portfolio holdings overlap. $^{2}$

Finally, to the extent that eligible bonds are not randomly assigned, there are potential sample selection concerns that complicate the interpretation of the policy impact results. For example, there might be (unobservable) factors - say, demand for IG bonds - that coincide with the introduction of the SMCCF and would have affected high exposure funds even in the absence of the program. An increase in the demand for IG bonds over the post-crisis period would lead to an upward bias in our estimates. To address identification, we exploit the 5-year maturity threshold for Fed purchase eligibility. The idea here is to refine the comparison between eligible vs. ineligible bonds to a sub-set of relatively more comparable bonds that are plausibly less likely to suffer from sample selection issues, which we implement by including in the sample only eligible bonds with a 5-year maturity and bonds with a 6-years maturity that would have been otherwise eligible because they satisfy the other eligibility criteria. For each fund, we construct the SMCCF share of eligible (ineligible) bonds held as weighted sums of dummies for eligible (ineligible) bonds with a 5-year (6-year) maturity, and then define as "treated" ("control") funds those in the top quartile of exposure to eligible (ineligible) bonds with 5-year (6-year) maturity. The results on the policy impact are robust to addressing identification with this approach, indicating that sample selection is unlikely to be the primary driver of our policy impact results. In fact, the economic

\footnotetext{
${ }^{2}$ Intuitively, this measure ranks funds based on whether they hold many bonds in common with other funds that are exposed to the Fed purchases. See Appendix A for details.
} 
significance of the estimates that address identification is similar to their OLS counterparts, with a one-standard deviation increase in eligibility associated with about 2.4 percentage point higher cumulative flows, which is about a third of the unconditional sample mean of cumulative flows over the post-crisis period.

Overall, our work complements recent studies of bond market disruptions in the COVID-19 crisis (Haddad, Moreira, and Muir, 2020, Kargar et al., 2020) by zeroing in on bond funds. Ma, Xiao and Zeng (2020) focus on bond funds' sales of liquid assets in response to outflows during the crisis. We also complement recent work by Pastor and Vorsatz (2020), who show that equity funds flows were relatively tranquil in the crisis. Our results on the policy impact complement recent work by O'Hara and Zhou (2020), Gilchrist et al. (2020), and Boyarchenko, Kovner, and Shachar (2020), which shows evidence of improved bond market liquidity and functioning due to the new role of the Fed as provider of a liquidity backstop or "market maker of last resort." Our results emphasize a novel "bond fund fragility channel" of the Fed liquidity backstop, as we document the effect of the Fed's announcements on reversing investors' redemptions from these funds and the effects this had on the market more generally. This helps to understand why the announcement of the Fed purchases led to such a powerful, broad-based, and speedy rally in credit markets despite the relatively limited scale of the actual purchases. An important policy implication of the transmission via funds is that the Fed can help improve access to bond financing and the resilience of the broader economy without necessarily having to actually take on significant credit risk. We also contribute to the literature on the transmission of unconventional monetary policy (see $\mathrm{Kr}$ ishnamurthy and Vissing-Jorgensen, 2011, for an overview and Grosse-Rueschkamp et al, 2019, for recent work), which has traditionally focused on banks, by highlighting a novel transmission mechanism via nonbank financial institutions. 


\section{Sizing Up Fragility: Baseline Estimates}

This section assesses fund fragility in the COVID-19 crisis using high-frequency real-time daily microdata on bond funds and ETFs. Large outflows were sustained for weeks, persistent and correlated across asset-classes within-funds. Two policy announcements by the Federal Reserve about extraordinary direct interventions in corporate-bond markets were effective at alleviating fund stress.

\subsection{Data}

The primary data for our analysis is high-frequency real-time information on daily fund flows and returns, as well as fund characteristics such as size (net assets) and age, from Morningstar. Via the Morningstar Direct platform, we retrieve information on the universe of open-end corporate-bond US funds and ETFs between January 2010 and April 2020, which leads to a sample of 4,952,183 fund share class-day observations for 4,142 $(1,511)$ unique share-classes (funds). In the second part of the analysis, we extend the sample through August 2020 to examine the post-crisis period. Because funds and ETFs differ along several important institutional dimensions and have been generally studied separately in the literature, we include only funds in the main analysis and examine ETFs separately (see Table 4 below). When necessary, we supplement the core data with additional data on fund characteristics and holdings as well as security-level bond information from various sources (see Appendix A for details on data sources and variable definitions).

Our main dependent variable of interest is fund flows. Mutual fund flows are estimated following the prior literature (e.g., Chevalier and Ellison, 1997), which is to define net flows of funds to mutual fund (share class) $i$ in day $t$ as the percentage growth of new assets. Mutual fund performance is measured using daily fund returns. For both flows and return, we show results using business-week (5-business-days) moving averages and weekly rates to mitigate the effect of high-frequency noise. 
Table 1 provides basic descriptive statistics. Sample coverage is comprehensive and comparable to other studies that use different data sources. Average fund flows and performance are also in line with previous studies. For example, Goldstein, Jiang, and Ng (2017) include 4,679 unique fund share classes and 1,660 unique corporate bond funds, with average monthly flows of $0.82 \%$ and $0.42 \%$, which are comparable to our implied average monthly counterparts of $0.64 \%$ and $0.28 \%$, respectively. Finally, there is substantial heterogeneity in fund flows and performance, as well as fund characteristics such as size. About $60 \%$ of the sample is comprised of investmentgrade funds and ETFs comprise $13 \%$ of the overall sample.

\subsection{Graphical Analysis}

Before proceeding to the formal regression analysis, we start with graphical analysis of fund flows. Corporate-bond markets in the U.S. experienced severe stress in March 2020. As market conditions deteriorated (see Appendix C for details), bond mutual funds experienced record selloffs.

Panel A of Figure 2 provides an assessment of the COVID-19 episode relative to the long-term historical experience of the corporate bond sector over the last decade. Corporate bond funds experienced aggregate net outflows in March of over 5\% relative to net assets, far greater than in previous stress episodes over the last decade. For example, the other large stress episode on record is the Taper Tantrum in the summer of 2013, which has been studied extensively in the literature (see, for example, Feroli et al., 2014). The Taper Tantrum led to aggregate monthly outflows of less than 3\% and, as we discuss in more detail below (see Table 6), to cumulative outflows for the average fund of about $2.2 \%$ in June-July of 2013 , far smaller than the about $10 \%$ outflows in February-March 2020. For reference, Morningstar estimated that redemptions from mutual funds totaled $\$ 326$ billion overall in March - more than three times the $\$ 104$ billion in outflows in October 2008, in the midst of the financial crisis. ${ }^{3}$ In our sample, redemptions in March totaled

\footnotetext{
${ }^{3}$ Appendix $\mathrm{C}$ discusses additional evidence that the stress on bond funds during the COVID-19 crisis was truly unprecedented based on the outsized number of funds that experienced very large daily outflows.
} 
$\$ 211 \mathrm{~B}$, which is about $10 \%$ of the sector assets under management as of February. For context, had the monthly redemptions kept their March pace, they would have been large enough to wipe out about a third of the sector over the course of just one quarter.

Zooming in more closely to the COVID-19 crisis period, Panel B of Figure 2 shows daily aggregate net flows of bond funds as a percentage of aggregate net assets. Two features stand out. First, daily outflows started in the last week of February and accelerated as the crisis precipitated in the third week of March after the declaration of a national emergency at the federal level on March 13, peaking at almost $1 \%$ of net assets. Second, outflows started to mitigate but continued in the last week of March, after the first policy announcement by the Federal Reserve about direct interventions in corporate-bond markets on March 23. The first announcement was about the Primary Market Corporate Credit Facility (PMCCF) and Secondary Market Corporate Credit Facility (SMCCF), which were designed to make outright purchases of corporate bonds issued by investment grade US companies, along with US-listed exchange-traded funds (ETFs) that invested in US investment grade corporate bonds. ${ }^{4}$ Outflow did not fully reverse until after the second announcement of a strengthening of the direct interventions on April 9. This second announcement involved a significant expansion of both facilities to $\$ 850 \mathrm{bn}$ (from less than $\$ 300 \mathrm{bn}$ ) and an extension of coverage of SMCCF to purchase high-yield bonds if they were investment-grade as of March 22 (See Appendix C for additional background information on the timeline of the crisis and graphical analysis). ${ }^{5}$

\subsection{Baseline Estimates}

Next, we provide a more formal assessment of fund fragility in the COVID-19 crisis using regression analysis. Table 2 presents our baseline estimates of the COVID-19 impact on fund fragility

\footnotetext{
${ }^{4}$ For PMCCF, see https://www.federalreserve.gov/newsevents/pressreleases/monetary20200323b.htm. For SMCCF, see https://www.federalreserve.gov/newsevents/pressreleases/monetary20200323b.htm.

${ }^{5}$ See https://www.federalreserve.gov/newsevents/pressreleases/monetary20200409a.htm. Before these announcments, other emergency policy measures by the Federal Reserve were announced between March 15 and March 18, including a rate cut to zero and the commercial paper funding facility (CPFF), the primary dealer credit facility (PDCF), and the money market funding facility (MMFF), which were not specifically targeted to the corporate bond market.
} 
using fund flows as the outcome variable (Columns 1 and 2 of Panels A-B, see Appendix B for estimating equation details). To clarify the impact on large outflows, we also report estimates of quantile regressions with fund flows as the outcome variables conditional on the bottom decile of the distribution (Column 3) and for a linear-probability model that uses an indicator for extreme outflows (a dummy for fund flows in the bottom decile of the distribution) as the outcome variable (Column 4). Panel A shows results for the overall Crisis dummy, while Panel B is for the more granular dummies for the crisis peak and policy response sub-periods.

In line with the graphical evidence, the coefficient on Crisis is negative (positive) and highly statistically significant for fund flows (large outflows) (Panel A), indicating that the COVID-19 shock was a significant stress event for funds. The result is robust to controlling for unobserved heterogeneity by including fund fixed-effects (Column 2, Panel A). And it is much stronger for funds in the bottom decile of flows (Column 3, Panel A). Finally, as for the timing of the effect, also in line with the graphical analysis, the bulk of the effect is concentrated in second half of March, with outflows peaking in mid-March after the declaration of the national emergency (Panel B). Outflows started to moderate significantly after the first policy announcement on March 23 ( $p$-value $=0.00$ for the test of the difference between the coefficient estimates of Peak and First Response), but did not fully reverse until after the second policy announcement on April 9 (Columns 1-2, Panel B).

Both the impact of COVID-19 on fund flows and that of the policy announcements are strongly economically significant. For example, the estimates in Column 2 of Panel A imply that the crisis led to about 30 bps decrease in weekly flows, which is roughly twice as large as the sample mean of flows, and those in Column 2 of Panel B imply that at the peak the crisis led to over 90 bps decrease in weekly flows and the first policy announcement reduced outflows by about 40 bps, which are about six and three times as large as the sample mean of flows, respectively. The effect of the crisis and the policy response was truly outsized for large outflows, with an 11 percent- 
age points increase in the likelihood of large outflows overall (Panel A), a 29 percentage points increase at the peak and an 11 percentage points reduction due to the first policy announcement (Panel B), which are either as large or thrice as large as the unconditional likelihood of large outflows. And the estimates in Column 3 imply that, at the peak, funds in the bottom decile of flows experienced outflows of over 3 percentage points and benefitted roughly twice as much from the policy announcements relative to other funds (Panel B).

To further put these estimates into context, we conduct two exercises. First, we examine how the crisis peak and the first policy announcement move a fund in the distribution of flows. The estimated 90 (40) bps decrease in weekly flows at peak (change after the first announcement) corresponds to about one and a half $(2 / 3)$ of an interquartile range movement in the distribution of fund flows (the interquartile range is 59 bps) - i.e., at the peak the impact of the crisis was larger than a move from the top to the bottom quartile of the distribution of flows and the impact of the first policy announcement was of the same order of magnitude. ${ }^{6}$ Second, the impact of the crisis is much larger than that of the largest previous stress episode in the last decade, the Taper Tantrum. The estimated coefficient on a dummy for the peak month of the Taper Tantrum, June 2013, implies an effect on flows of about 19 bps, which is less than a quarter of the estimated peak effect in Panel B.

Panel C of Table 2 examines the impact of the crisis and policy response on two additional aspects of fund fragility, persistence and co-movement of fund flows. We estimate the baseline equation using as the dependent variable a dummy for multiple (2 or 3) consecutive days of large outflows (Columns 1-2) and a dummy for multiple (2 or 3) share-classes experiencing large outflows within any given fund (Columns 3-4), in turn. We again show results for the more granular dummies for the crisis peak and policy response sub-periods. The timing of the impact on both

\footnotetext{
${ }^{6}$ We also compare the marginal effect of the crisis to that of standard fund-level covariates, such as fund size. We calculate the marginal effect by multiplying the respective estimates by the standard deviation of fund size. The marginal impact of the crisis is of the same order of magnitude as that of fund size (1-standard deviation change in size is associated with a 30 bps change in flows), which further corroborates the notion that the COVID-19 crisis was an economically significant stress event for funds.
} 
the persistence and co-movement of large fund outflows is in line with the baseline estimates for flows, with the bulk of the effect in the second half of March. As for the impact of the policy interventions, there is evidence of partial and then fuller reversals after the first and second policy announcements, respectively, but there are indications of continued strains based on these measures.

The impact of the crisis on the additional measures of stress is also strongly economically significant. For example, the estimates in Columns 1 and 3 of Table 2 (Panel C) imply that at the peak the stress was severe, with an implied 22 percentage points increase in the likelihood of 2-day large outflows and an implied 38 percentage points increase in the likelihood of large outflows for at least two share-classes within-fund, both more than thrice as large as their respective unconditional likelihood. Again, for historical comparison, the estimated coefficients on a dummy for the peak month of the Taper Tantrum, June 2013, imply an effect of about 9 percentage points for 2-day large outflows and 15 percentage points large outflows for at least two share-classes within-fund, respectively, which are roughly half as large as the estimated peak effects in Panel C. ${ }^{7}$

\section{Sources of Fragility}

Having established that the COVID-19 crisis was a unique stress event for corporate bond funds, next we use sample-split analysis to explore which economic mechanisms were at play. We provide comprehensive evidence that fund illiquidity and vulnerability to fire-sale spillovers were important sources of fragility, which each account for up to about half of the cumulative outflows throughout the stress episode. In addition, these more fragile funds benefitted relatively more from the announcement effect of the Fed facilities.

\footnotetext{
${ }^{7}$ Appendix Tables A.1-A.2 show that the baseline results are robust to including ETFs in the sample and to clustering standard errors at the fund level. Appendix Table A.3 provides additional coefficient estimates of the timing of the evolution of the crisis before the peak (see Appendix $C$ for details).
} 


\subsection{Fund Illiquidity and Fire-Sale Vulnerability}

One potential economic mechanism at play is fund illiquidity. As emphasized in Chen, Goldstein, and Jiang (2010) and Goldstein, Jiang, and Ng (2017), this mechanism is based on the idea that strategic complementarities exist among investors in corporate bond mutual funds driven by the illiquidity of their assets. When investors redeem their shares, they get the net asset value as of the day of redemption. The fund then has to conduct costly liquidation that hurts the value of the shares for investors who keep their money in the fund. Hence, the expected redemption by some investors increases the incentives of others to redeem. Greater illiquidity at the level of the fund is expected to generate stronger strategic complementarities among investors when deciding to redeem their shares. Funds with more liquid assets will not have to bear high costs liquidating their positions on short notice to meet redemption requests, mitigating the negative externalities following redemptions. Thus, fund liquidity should alleviate the tendency of investors to run.

Table 3 examines the illiquidity mechanism using sample-split analysis. We report the estimates from the baseline equation using fund flows as the outcome variable for different subsample splits based on empirical proxies for the extent to which funds have more illiquid bond holdings. The gist of these tests is to examine whether the impact of the COVID-19 crisis on fund flows is more pronounced for those funds that the theory predicts should be more prone to runs in the cross-section. To measure asset liquidity at the fund level, we use two main measures, which are standard in the literature: the Roll (1984) measure and the bid-ask spread. The Roll measure captures the serial covariance of intraday bond returns. Intuitively, bond prices bounce back and forth between the bid and ask prices, and hence higher bid-ask spreads would lead to higher negative covariance between consecutive returns. We split the sample into two sub-samples based on the top vs. bottom quartiles of each of these measures at the beginning of the sample period (as of 2018Q4), in turn. Columns 1-4 of Panel A show results for the overall Crisis dummy, while Panel B is for the more granular dummies for the crisis peak and policy response sub-periods. 
In line with theory, the coefficient on Crisis is reliably negative and highly statistically significant but only for illiquid funds (Columns 1-4, Panel A), indicating that illiquidity was an important economic mechanism through which the COVID-19 shock led to fund stress. The result is robust across the two holding-based liquidity measures, and the difference between the estimated coefficients in the two sub-samples of liquid vs. illiquid funds is large and statistically significant for both measures ( $\mathrm{t}$-stat=-4.46 and -3.70 for the Roll (1984) measure and the bid-ask spread, respectively). For example, the estimates for the Roll measure in Columns 1-2 of Panel A imply that illiquid funds were much more fragile in the crisis, as they experienced outflows that were about four times as large, on average, relative to those of liquid funds. The difference between the two groups squares well with the size of the estimates in Goldstein, Jiang, and $\mathrm{Ng}$ (2017), who find that the fund flows are up to three times as sensitive to performance for illiquid funds (see their Table 5).

The timing of the effect provides further corroborating evidence that illiquidity led to fund fragility in the crisis. First, the coefficient estimates on the Peak (Mar 13-23, 2020) dummy are negative in both sub-samples, but are outsized for illiquid funds. Second, the coefficient estimates on the First Response (Mar 23-Apr 9, 2020) dummy remain negative, but are comparable between sub-samples and are of an order of magnitude smaller than those on Peak, indicating that illiquid funds benefitted relatively more from the policy announcement. After the first policy announcement, reduction in outflows relative to the peak is of up to $80 \mathrm{bps}$ for illiquid funds. The coefficient estimates on the Second Response (Apr 9-17, 2020) dummy in Panel B are generally not statistically significant, indicating that the effect reversed for both liquid and illiquid funds. Low-rated funds, which are also arguably more illiquid, benefitted the most from the April 9 policy announcement that was specifically targeted to support them. Finally, additional coefficient estimates on the earlier stages of the crisis in Appendix Table A.4 are reliably positive only for relatively more liquid funds, indicating that outflows started earlier in March for relatively more illiquid funds. ${ }^{8}$

\footnotetext{
${ }^{8}$ While the relative inflows for liquid funds earlier on in March certainly helped to reduce the impact of the COVID-
} 
Another potential economic mechanism is costly fire-sales. As emphasized by a classical literature starting from Shleifer and Vishny $(1992,1997)$, in the presence of a downward-sloping demand for corporate bonds, fire-sales of a fund's portfolio securities - i.e., sales that are forced by redemptions - have a price-impact. ${ }^{9}$ By depressing security prices, flow-related sales lead to spillovers because the valuation losses hurt the performance of peer funds that hold the same securities. In turn, spillovers may lead to redemptions at peer funds through the performanceflow relationship. Falato, Hortacsu, Li, and Shin (2019) provide direct evidence that there are sizable fire-sale spillovers in debt markets and that spillovers aggravate a specific type of market instability - volatility - by amplifying the effect of an initial shock to fund flows that is otherwise unrelated to fundamental asset values. The mechanism is that outflows at peer funds lead to a second round of outflows that further depresses bond prices over and above the initial effect of a given adverse shock. As a result, spillovers lead to higher volatility by increasing the exposure of funds and bonds to non-fundamental risk.

To examine the fire-sale mechanism, Table 3 reports the estimates for a sub-sample split based on an empirical proxy for the extent to which funds are vulnerable to fire-sale spillovers. The proxy is constructed as Falato et al. (2019), to which we refer to details. The vulnerability measure captures the degree of overlap between the bond holdings of a given fund and those of other funds, as well as the strength of the price-impact of flow-driven fire sales. Intuitively, the measure ranks as more vulnerable funds for which peer outflows are more likely to lead to own outflows and it is higher whenever 1) there is a higher degree of overlap in bond holdings with other funds; and 2) debt market conditions are such that forced sales have a larger price impact. We split the sample into two sub-samples based on the top vs. bottom quartiles of the fire-sale vulnerability measure at the beginning of the sample period (as of 2018Q4). Columns 5-6 of Panel A show

19 crisis on the overall sector, they were not large enough to offset the earlier outflows for illiquid funds combined with the peak outflows for all funds, leading to the large aggregate outflows in March shown in Figure 2.A.

${ }^{9}$ Several factors have been identified in the literature as potentially leading to downward-sloping demand, including illiquidity due to transaction costs as well as, more broadly, slow-moving capital factors that make high-valuation bidders relatively scarce and lead to arbitrage persistence (see, for example, Mitchell, Pedersen, and Pulvino (2007) and Duffie (2010)). 
results for the overall Crisis dummy, while Columns 1-2 of Panel C are for the more granular dummies for the crisis peak and policy response sub-periods.

The results are stronger in the sub-sample of more vulnerable funds (Panel A, Columns 5-6) and the difference between the estimated coefficients on Crisis in the two sub-samples of more vs. less vulnerable funds is large and statistically significant $(\mathrm{t}-\mathrm{stat}=-1.84)$, indicating that fire-sale spillovers were another mechanism through which the COVID-19 shock led to fund stress. The estimates imply that vulnerable funds were much more fragile in the crisis, as they experienced outflows that were almost twice as large, on average, relative to those of less vulnerable funds. The size of the difference between the estimates in the two subgroups implies that vulnerable funds experienced about half of a percentage point higher outflows on a monthly basis, which squares well with the 0.7 percentage point effect of fire-sale spillovers on monthly outflows estimated in Falato et al. (2019) (see their Table 5). As for the timing of the effect, similar to the liquidity results, the differences between the two groups are even more pronounced at the peak, consistent with mid-March being the phase of highest fragility. Also consistent with heightened fragility at the peak, the first policy announcement benefitted relatively more the vulnerable funds with the reduction in outflows relative to the peak at about 50 bps (Panel C, Columns 1-2). ${ }^{10}$

\subsection{ETFs and Fund Sector Exposure}

Next, we inspect ETFs and fund sector exposure to gain further insight into the sources of fragility.

First, we examine whether ETFs were more fragile or rather more resilient relative to similarly performing open-end funds. The fragility of ETFs is ultimately an empirical question. On the one hand, ETFs share some features of closed-end funds, in that most of their investors can only trade their shares and not directly redeem. Only a sub-set of their investors (called "authorized

\footnotetext{
${ }^{10}$ In Columns 3-6 of Panel C, we split the sample based on two additional measures: fund age (Columns 3-4) and maturity (Columns 5-6). Younger funds may face higher illiquidity and fire-sale costs either because they are run by less experienced managers or because there is more uncertainty about their performance. Longer maturities may also exacerbate runs because bonds with longer maturity have higher interest rate risk relative to bonds with shorter maturities. Consistent with this reasoning, the results for these additional measures indicate that overall impact of the COVID-19 shock was stronger for younger funds and those with longer maturities of their bond holdings.
} 
participants," APs) can redeem bundles of their shares in-kind, but they may decide not to. Thus, AP redemptions move less than one-to-one in response to end-investors' ETF sales, which may lead to smaller outflows. This makes them less prone to liquidity mismatch and arguably less fragile than open-end funds. On the other hand, ETFs tend to attract a different clientele of institutional investors with a stronger preference for liquidity, which may make them more fragile than open-end funds (see Dannhauser and Hoseinzade, 2019).

The estimates from a matched-sample analysis of ETF flows relative to similar bond funds based on performance as well as age and size are shown in Table 4, for the overall Crisis dummy in Panel A and for the more granular dummies for the crisis peak and policy response sub-periods in Panel B (see the table caption for specification details). The estimates in Panel A indicate that ETFs were relatively less fragile in the COVID-19 crisis, as they experienced smaller outflows (Column 1) and were less likely to experience large, persistent, and correlated outflows (Columns 2-4, respectively) during the crisis. The size of the difference between outflows of ETFs and those of comparable open-end funds is strongly statistically and economically significant. For example, the estimate in Column 2 implies that ETFs had a 7 percentage point lower likelihood of large outflows, which is about as large as the unconditional likelihood of large outflows. The estimates in Panel B confirm that ETFs were less likely to experience large, persistent, and correlated outflows both at the peak of the crisis and after the Fed announcements (Columns 2-4, respectively). Overall, the results indicate that ETFs were more resilient than open-end funds in the crisis. The stronger reversal of outflows after the policy announcements is also consistent with the fact that the Fed programs included direct purchases of ETFs.

Finally, to zoom in on the unique forces at play in the COVID-19 episode we classify funds based on their exposure to the crisis. Fahlenbrach, Rageth and Stulz (2020) look at stock-price reactions for firms in different industries and compare those in highly affected industries to those in less affected industries. We build on their classifications and using the particular bonds held 
by different funds, we compare outflows from more affected funds to those from less affected funds. Table 5 summarizes the results of the analysis by fund sector exposure (see Appendix B for details of the estimating equation). In line with the main estimates, the coefficient estimate on the interaction term of Crisis with High Exposure Fund is negative and highly statistically significant (Columns 1-2), indicating that funds holding bonds in affected industries suffered more severe stress in the COVID-19 crisis. The result is robust to controlling for unobserved heterogeneity by including fund fixed-effects (Column 2). The estimates for the timing of the effect indicate that funds holding bonds in the most affected industries suffered bigger outflows at the peak of the crisis in mid-March and experienced a stronger reversal following the first Fed announcement, with the greater reduction in outflows relative to the peak estimated at about 75 bps (Columns 3-4). These results further support the idea that the particular forces that were in play during the COVID-19 crisis affected the funds investing in corporate bonds. ${ }^{11}$

\subsection{Quantifying the Sources of Fragility}

How far can one go toward explaining the impact of the COVID-19 crisis on fund fragility with the main mechanisms we highlighted, illiquidity and vulnerability to fire-sales? We now use an Oaxaca-Blinder style decomposition to better quantify the relative importance of different explanations for the spike in outflows during the crisis.

As shown in Panel A of Table 6, corporate bond funds experienced cumulative outflows of about $10 \%$ relative to their net assets, on average, in the period from February 1 to March 31, 2020 and of about 7\% in the period from March 1 to April 30, 2020. Confirming our findings from the sample-split analysis, average cumulative outflows were even more severe for illiquid funds and for funds that were vulnerable to fire-sales. Illiquid funds experienced cumulative outflows of about $19 \%$ relative to their net assets, on average, in the period from February to

\footnotetext{
${ }^{11}$ Appendix Table A.5 provides additional corroborating evidence on fund fragility from the flow-performance relation (see Appendix C for details). Appendix Tables A.6 and A.7 provide additional coefficient estimates on the timining of the evolution of the crisis.
} 
March 2020 and of about 15\% in the period from March to April 2020. Funds that were vulnerable to fire-sales experienced cumulative outflows of about $17 \%$ and $11 \%$ relative to their net assets, on average, over the two crisis sub-periods. Finally, fragile funds, based on a fragility factor constructed by aggregating across the proxies with principal component analysis, experienced cumulative outflows of about $23 \%$ and $18 \%$ relative to their net assets, on average, over the two sub-periods.

To gauge the contribution of the different sources of fragility to cumulative outflows in the crisis, we use an Oaxaca-Blinder style regression-based approach. For example, take illiquidity. We split the sample into two sub-samples based on top vs. bottom quartiles of the illiquidity proxy (Roll). We estimate the baseline equation using two-month cumulative fund flows as the outcome variable in the sub-sample of liquid funds. We store the estimated coefficients and use them to predict cumulative flows for illiquid funds, which provides the counterfactual of flows for illiquid funds "as if" they were liquid. Finally, we take the difference between cumulative flows and predicted cumulative flows for illiquid funds, which is our measure of the impact of COVID19 on cumulative flows that can be attributed to illiquidity. We tabulate the \% share explained by illiquidity, which is the ratio of the mean difference between cumulative flows and predicted cumulative flows divided by mean cumulative flows for illiquid funds.

The results of this decomposition are shown in Panel A of Table 6. Both mechanisms can explain a sizable fraction of the spike in outflows during the COVID-19 crisis. Specifically, the illiquidity mechanism can explain about $40 \%$ of the mean cumulative outflows from February to March 2020 and about 28\% of the mean cumulative outflows from March to April 2020. Fire-sale vulnerability can account for about $56 \%$ of the mean cumulative outflows from February to March 2020 and about 37\% of the mean cumulative outflows from March to April 2020. For reference, we also report results of the same approach for COVID-sector exposure. The explanatory power of illiquidity and fire-sale vulnerability is roughly comparable to this benchmark for the size of the 
shock, with COVID-19 sector exposure accounting for about $64 \%$ of the mean cumulative outflows from February to March 2020 and about 55\% of the mean cumulative outflows from March to April $2020 . .^{12}$

\section{A Bond Fund Fragility Channel of the Fed SMCCF}

Our evidence so far indicates that the two main Fed announcements helped to stop the panic and reverse outflows. But how sustained was the rebound over the post-crisis months and did the Fed policy actions continue to help over the longer run? Next, we examine in detail the impact of the policy response over the post-crisis period. Growing evidence points to improved bond market liquidity and functioning post-crisis, largely owing to the new role of the Fed as provider of a liquidity backstop or "market maker of last resort" (see O'Hara and Zhou, 2020, Gilchrist, Wei, Yue, and Zakrajsek, 2020, and Boyarchenko, Kovner, and Shachar, 2020). By improving the liquidity of the bonds held by funds, the policy action should be expected to reduce fund fragility based on both the main mechanisms we emphasized, because both liquidity mismatch and firesale costs are lower when bond liquidity improves. Importantly, as funds get less fragile, there may be positive spillovers to primary bond markets and other funds that hold similar securities.

To investigate these possibilities, we extend our sample coverage through the end of August 2020. As shown in Panel B of Table 6, in the post-crisis period between April and August fund flows continued to rebound in line with the broader improvements in bond market conditions, with corporate bond funds posting cumulative inflows of over $9 \%$ relative to their net assets, on average. As a result, over the February to August period that combines crisis and post-crisis, flows ended up fully recovering, on average. To explore the role of the Fed facilities, we retrieve information on the SMCCF purchase eligibility from the term sheet of the SMCCF. The eligibility criteria are: maturity of under 5 years, domiciled in the US, not an insured depository institu-

\footnotetext{
${ }^{12}$ Appendix Table A.7 shows that the sample split results are robust to limiting the sample to just investment-grade funds or to orthogonalizing each proxy with respect to the others (see Appendix $C$ for details).
} 
tion, and rated investment grade as of March 22, 2020 and not lower than BB+ afterwards ("fallen angels"). ${ }^{13}$ Intuitively, a fund with high exposure to the Fed SMCCF holds a high proportion of bonds that are eligible for purchases by the SMCCF. To operationalize this measure, we flag each bond that satisfied the eligibility criteria and define the SMCCF Share for each fund as a weighted sum (according to the fund's portfolio weights as of February 2020) of the bond-specific indicators for whether any particular bond was eligible for purchase by the SMCCF.

In Panel A of Table 7, we report results of cross-sectional regressions of cumulative fund flows over the post-crisis period on the fund-level SMCCF share. The estimates in Columns 1 and 4 indicate that there is a strongly statistically significant positive (negative) relation between the SMCCF share and fund flows (large outflows). The relation is also economically significant, with a one-standard deviation increase in exposure to bond that are eligible for purchase by the Fed SMCCF being associated with about 3 percentage point higher cumulative flows, which is roughly a third of the unconditional sample mean flows over the post-crisis period. In line with the results on outflows in the crisis, exposure to the Fed SMCCF benefitted relatively more the funds that were more fragile, either because they were more illiquid (based on the Roll proxy, Columns 2 and 5) or because they were more vulnerable to fire-sales (Columns 3 and 6). ${ }^{14}$

Panel B of Table 7 examines the transmission of the Fed SMCCF via funds - i.e., whether fund exposure to bonds that are eligible for purchase by the Fed SMCCF had a spillover effect on other firms' access to bond financing in the primary markets. We build on the evidence in Zhu (2020) that funds that hold a firm's existing bonds have a high propensity to acquire additional new issuances from the same firm. Thus, firms whose existing bondholders hold more bonds that are eligible for purchase by the Fed SMCCF should benefit from the reduction in their bondholders' fragility. We construct an issuer-level version of the SMCCF Share variable by taking an average

\footnotetext{
${ }^{13}$ Based on the monthly public Fed releases, actual purchases started mid-June and through August 31 totalled over $\$ 12$ billion (available at: https://www.federalreserve.gov/reports-to-congress-covid-19.htm).

${ }^{14}$ See Appendix Table A.9 for the additional estimates in the sub-samples with low illiquidity and vulnerability. In line with the main analysis, the estimates in these sub-samples are smaller and generally not statistically significant.
} 
of the fund-level shares across outstanding issues for any given issuer. We report results of crosssectional regression of primary market bond issuance volumes and spreads as well as secondary market bond spreads on issuer level exposure to the SMCCF. All specifications include controls for bond size, rating, and maturity. An important omitted variable concern with our spillover measure is that bonds that are ranked higher based on the measure are more likely to be eligible, if funds focus on similar bonds in their portfolio holding decisions. To mitigate this issue, which is an instance of the classic reflection problem discussed by Manski (1993), we control for direct effects by including a dummy for the SMCCF eligibility of any given bond. The results indicate that issuers whose existing bondholders have higher exposure to bonds that are eligible for purchase by the Fed SMCCF experience better terms in the primary markets, with higher bond issuance volumes (Column 1) and lower issuance spreads (Column 2). Also spreads in the secondary markets are lower for these firms (Column 3). Finally, these effects are more pronounced for bonds held by more fragile funds based on their illiquidity (again measured by the Roll proxy).

Finally, in Panel C of Table 7 we explore a second aspect of the transmission of Fed SMCCF - i.e., whether not just the funds that held bonds that were eligible for purchase by the Fed, but also their peers benefitted. We define peer funds similar to Falato et al. (2019) based on portfolio holdings overlap. Specifically, we construct a Peer SMCCF Share by taking the weighted sum (according to any given fund's own portfolio weights) of the bond-level SMCCF share. Intuitively, this measure ranks funds based on whether they hold many bonds in common with other funds that are exposed to the Fed SMCCF. To control for direct effects, in all regressions we control for exposure to the Fed SMCCF by including a dummy for high (top quartile) SMCCF Share. ${ }^{15}$ The results for large outflows (Columns 4 to 6) indicate that there are significant spillovers of the Fed SMCCF on peer funds. For example, the estimates in Column 4 imply that a one-standard deviation increase in the peer share variable is associated with 2 percentage point lower likelihood

\footnotetext{
${ }^{15}$ The reason for including a dummy for high exposure rather than the exposure variable itself is to mitigate multicollinearity concerns.
} 
of large outflows, which is about the same order of magnitude as the direct effect in Panel A. Again, illiquid funds and those that are vulnerable to fire-sales have larger spillovers (Columns 5 and 6 , respectively).

The analysis so far relies on cross-sectional differences across funds based on their bond holdings. To the extent that eligible bonds are not randomly assigned, there are potential sample selection concerns that complicate the interpretation of the results. For example, there might be (unobservable) factors - say, demand for IG bonds - that coincide with the introduction of the SMCCF and would have affected high exposure funds even in the absence of the program. An increase in the demand for IG bonds over the post-crisis period would lead to an upward bias in our estimates. To address identification, we exploit the 5-year maturity threshold for Fed purchase eligibility. The idea here is to refine the comparison between eligible vs. ineligible bonds to a sub-set of relatively more comparable bonds that are plausibly less likely to suffer from sample selection issues. To that end, we now include in the sample only eligible bonds with a 5-year maturity and bonds with a 6-years maturity that would have been otherwise eligible because they satisfy the other eligibility criteria. For each fund, we construct the SMCCF share of eligible (ineligible) bonds held as weighted sums of dummies for eligible (ineligible) bonds with a 5-year (6-year) maturity. We define SMCCF Treated funds as those in the top quartile of exposure to eligible bonds with 5-year maturity and compared them to control funds, which are those in the top quartile of exposure to ineligible bonds with 6-year maturity. ${ }^{16}$

The results of the analysis that addresses identification are reported in Table 8. In line with the previous estimates, the estimates for the treatment dummies remain strongly statistically and economically significant robustly across all of the three sets of outcomes in Panels A to C, indicating that sample selection is unlikely to be the primary driver of the estimates of the policy impact.

\footnotetext{
${ }^{16}$ The issuer-level and peer versions of the treatment dummies are defined analogously. See Appendix A for details. Further corroborating the validity of the design, treated funds are well-balanced along observable pre-treatment fund characteristics ( $\mathrm{t}$-stat of the difference between treated and control funds is 1.01 for fund size, and 1.12 for fund performance).
} 
For example, Column 1 of Panel A implies that SMCCF treatment is associated with about 7 percentage point higher cumulative flows, which is about as large as the unconditional sample mean of cumulative flows over the post-crisis period. To further gauge economic significance, the estimates imply that a one-standard deviation increase in the SMCCF treatment is associated with about 2.4 percentage point higher cumulative flows, which is about as large as its OLS counterpart of 3 percentage points in Table $7 .{ }^{17}$

Overall, the results in this section further corroborate the evidence from the earlier evidence from the announcement effect of the facilities. The results indicate that the Fed actions helped to reduce fund fragility after the crisis and particularly so for more fragile funds. Importantly, funds transmitted the effect of the Fed actions more broadly to primary market issuance and spreads via exposure of issuers' existing bondholders to the SMCCF - and to other funds - via common bond holdings. There are several takeaways of this novel "bond fund fragility channel" of the Fed liquidity backstop. First, by providing a liquidity backstop for the bonds, the new Fed policy served as a financial stability tool also for bond funds because it mitigated liquidity mismatch and fire-sale costs associated with illiquidity of fund holdings. As such, it served as an effective substitute for a separate ad-hoc facility to stabilize the bond fund sector, such as the Money Market Mutual Fund Liquidity Facility (MMLF) which was used to stabilize money market funds.

Second, the spillover effect on issuers can help to explain why the Fed actions unleashed a wave of issuance by both investment-grade and high-yield firms despite the relatively small scale of actual secondary-market purchases and no actual Fed purchases in the primary market. As such, an important policy implication of the transmission via funds is that the Fed can help improve access to bond financing and the resilience of broader economy without necessarily having to actually take on significant credit risk. Finally and related, the spillover on peer funds also contributes to explain why the Fed actions led to such a powerful, broad-based, and speedy rally

\footnotetext{
${ }^{17}$ Also in line with the OLS counterparts, the SMCCF treatment leads to about twice as large a reduction in large outflows for high illiquidity and vulnerability funds relative to low illiquidity and vulnerability funds.
} 
in credit markets despite the relatively limited scale of the actual purchases. As such, they point to an additional important benefit of the Fed liquidity backstop, to restore market functioning by halting investor runs on funds which could otherwise lead to fund closures and issuer defaults.

\section{Conclusion}

Non-bank intermediaries such as mutual funds and ETFs have become important players in debt markets over the last decade, but whether and why they are vulnerable and prone to fragility in times of stress remains an openly debated academic and policy question. And even less is known about whether and how Fed policy actions help to stabilize funds and increase their resilience. In order to understand the fragility of the asset management sector, we have used rich high-frequency microdata on individual fund flows, returns, and holdings of corporate debt funds and ETFs, and the COVID-19 crisis as a laboratory to evaluate different forces that lead to fragility. We have shown evidence that funds were under severe stress in the COVID-19 crisis and particularly so those that were illiquid and vulnerable to fire-sales. We have also shown that fund fragility provides a novel perspective over the transmission of unconventional monetary policy via non-bank financial institutions.

When thinking about the implications for the future of investment funds in illiquid markets, we caution that massive Fed intervention in the market should not be expected to become the norm (see Stein, 2012 for an analysis of the link between conventional monetary policy and financial stability). Hence, some of the structural fragilities in the way investment funds operate in illiquid markets, which we confirm here to have played a role in the recent episode, have to be addressed more directly. One prominent tool - swing pricing - which is meant to mitigate the run dynamics by penalizing investors for withdrawing when many other investors withdraw, has been introduced in the US in November 2018, but is still not implemented. Recent research by Jin, Kacperczyk, Kahraman, and Suntheim (2020) demonstrates its stabilizing effect in the UK where 
it was implemented much earlier. The effectiveness of this tool in a major stress event like that studied here remains an open question. Similarly, there are implications for the way funds manage their liquidity, which is a topic that has been studied before the COVID-19 crisis by Chernenko and Sunderam (2016), Morris, Shim, and Shin (2017), and Zeng (2017). 


\section{References}

[1] Bernanke, B. and J. Yellen, 2020, "The Federal Reserve Must Reduce Long-Term Damage from Coronavirus," Financial Times, March 18.

[2] Boyarchenko, N., Kovner, A. and Shachar, O., 2020, "It's What You Say and What You Buy: A Holistic Evaluation of the Corporate Credit Facilities," NY Fed Staff Report 935.

[3] Brunnermeier, M., S. Rother, and I. Schnabel, 2019, "Asset Price Bubbles and Systemic Risk," Review of Financial Studies, forthcoming.

[4] Chen, Qi, Itay Goldstein, and Wei Jiang, 2010, "Payoff Complementarities and Financial Fragility: Evidence from Mutual Fund Outflows," Journal of Financial Economics, 97 (2), 239-62.

[5] Chernenko, S., and A. Sunderam, 2016, "Liquidity Transformation in Asset Management: Evidence from the Cash Holdings of Mutual Funds," mimeo, Harvard Business School.

[6] Chevalier, J., and G. Ellison, 1997. "Risk taking by mutual funds as a response to incentives," Journal of Political Economy 105:1167-200.

[7] Coval, J., and E. Stafford, 2007. "Asset fire sales (and purchases) in equity markets," Journal of Financial Economics 86:479-512.

[8] Dannhauser, C. D and S. Hoseinzade, 2019, "Corporate Bond ETFs: Innovative, but Not Inconsequential," mimeo, Villanova University.

[9] Duffie, Darrell, 2010, "Asset Price Dynamics with Slow-Moving Capital," The Journal of Finance, 65 (4), 1238-1268.

[10] Fahlenbrach, R., K. Rageth, and R. Stulz, 2020, "How Valuable is Financial Flexibility When Revenue Stops? Evidence from the COVID-19 Crisis," OSU WP 2020-07. 
[11] Falato, A., A. Hortacsu, D. Li, and C. Shin, 2019, "Fire-Sale Spillovers in Debt Markets," Journal of Finance, forthcoming.

[12] Federal Reserve Board, 2020, "Financial Stability Report," May.

[13] Feroli, Michael, Anil K. Kashyap, Kermit Schoenholtz, and Hyun Song Shin, 2014, "Market Tantrums and Monetary Policy," U.S. Monetary Policy Forum White Paper.

[14] Gilchrist. S.., B. Wei, V. Z. Yue, and E. Zakrajsek, 2020, "The Fed Takes on Corporate Credit Risk: An Analysis of the Efficacy of the SMCCF," NBER WP No. 27809.

[15] Goldstein, I., H. Jiang, and D. T. Ng, 2017, "Investor Flows and Fragility in Corporate Bond Funds," Journal of Financial Economics, 126, 592-613.

[16] Grosse-Rueschkamp. B., S. Steffe, and D. Streitz, 2019, "A Capital Structure Channel of Monetary Policy," Journal of Financial Economics, 133, 357-378.

[17] Haddad, V., A. Moreira, and T. Muir, 2020, "When Selling Becomes Viral: Disruptions in Debt Markets in the COVID-19 Crisis and the Fed's Response," NBER WP 27168.

[18] Jin, D., M.T., Kacperczyk, B. Kahraman, and F. Suntheim, 2020, "Swing Pricing and Fragility in Open-end Mutual Funds," mimeo, University of Oxford.

[19] Kargar, M., B. Lester, D. Lindsay, S. Liu, P. Weill, D. Zúñiga, 2020, "Corporate Bond Liquidity During the COVID-19 Crisis," NBER Working Paper No. 27355.

[20] Krishnamurthy, A and A. Vissing-Jorgensen, 2011, "The Effects of Quantitative Easing on Interest Rates: Channels and Implications for Policy," BPEA, 43, 215-265.

[21] Manski, C., 1993. "Identification of Endogenous Social Effects: The Reflection Problem," Review of Economic Studies 60, pp. 531-542.

[22] Mitchell, Mark, Lasse Heje Pedersen, and Todd Pulvino, 2007, “Slow Moving Capital," American Economic Review, May 2007, 97 (2), 215-220. 
[23] Morris, S., I. Shim, and S.H. Shin, 2017, "Redemption Risk and Cash Hoarding by Asset Managers," BIS Working Paper No. 608.

[24] O'Hara, M. and Zhou, X.A., 2020, "Anatomy of a Liquidity Crisis: Corporate Bonds in the COVID-19 Crisis," Journal of Finance Economics, forthcoming.

[25] Pastor, L. and M. B. Vorsatz, 2020, "Mutual Fund Performance and Flows During the COVID19 Crisis," Review of Asset Pricing Studies, forthcoming.

[26] Petersen, M., 2006, "Estimating Standard Errors in Finance Panel Data Sets: Comparing Approaches," Review of Financial Studies, 22: 435-480.

[27] Phillips, P. C. B., S. Shi, and J. Yu, 2015, "Testing for Multiple Bubbles: Historical Episodes of Exuberance and Collapse in the S\&P 500," International Economic Review, 56(4), 1043-1078.

[28] Shleifer, Andrei, and Robert Vishny, 1992. "Liquidation Values and Debt Capacity: A Market Equilibrium Approach," Journal of Finance 47, 1343-1366.

[29] Shleifer, Andrei, and Robert W. Vishny, 1997, "The Limits of Arbitrage," Journal of Finance $52,35-55$.

[30] Stein, Jeremy C., 2012. "Monetary Policy as Financial Stability Regulation," Quarterly Journal of Economics 127, pp. 57-95.

[31] Vissing-Jorgensen, A., 2020, "The Case for Federal Reserve Corporate Bond Purchases," mimeo, University of California Berkeley.

[32] Zeng, Y., 2017, "A Dynamic Theory of Mutual Fund Runs and Liquidity Management," mimeo, University of Washington.

[33] Zhu, Q., 2020, "Capital Supply and Corporate Bond Issuances: Evidence from Mutual Fund Flows," Journal of Financial Economics, Forthcoming. 


\section{Appendix A: Details of Variable Definitions}

The variables used in this paper are extracted from four major data sources for the 2010M12020M8 period: daily mutual fund flows, net assets, and returns from the Morningstar Database; $^{18}$ quarterly mutual fund characteristics from the CRSP Mutual Fund Database; quarterly security-level holdings of fixed income securities by U.S.-domiciled mutual funds from Thompson Reuters/Lipper eMAXX database when available and the CRSP Mutual Fund Database otherwise; security-level data on corporate bond trading volume and liquidity from TRACE, and bond maturity and ratings from FISD and the three major credit rating agencies (Fitch, Moody's, and S\&P).

The variables are defined as follows:

Main Fund-Level Outcomes:

Flows $(\%)$ is defined as $\mathrm{FLOW}_{j, t}=\left(\mathrm{TNA}_{j, t}-\left(1+\mathrm{r}_{j, t}\right) \mathrm{TNA}_{j, t-1}\right) / \mathrm{TNA}_{j, t-1}$, where $\mathrm{TNA}_{j, t-1}$ is the total net assets under management at the end of the previous period, and $r_{j, t}$ is the return (net of fees and expenses) over the period. ${ }^{19}$

Large Outflows is defined as a dummy that takes value of one for fund-day observations in the bottom decile of the distribution of fund flows.

2-day (3-day) Large Outflows is defined as a dummy that takes value of one for fund-day observations corresponding to 2 (3) consecutive days in the bottom decile of the distribution of fund flows.

2+SC (3+SC) Large Outflows is defined as a dummy that takes value of one for fund-day observations corresponding to funds with at least 2 (3) share classes in the bottom decile of the distribution of fund flows.

\section{Fund Characteristics:}

Return (\%) is the daily net fund return.

Illiquidity (Roll). We use TRACE transaction data to calculate various daily liquidity measure for each bonds. We then take the within-quarter average of daily measures to get quarterly liquidity measure. Roll's bid-ask spread based on Roll's (1984):

$$
L i q_{i, d}^{R o l l}=\sqrt[2]{-\operatorname{cov}\left(\Delta P_{i, d}^{j}, \Delta P_{i, d}^{j-1}\right)}
$$

where $\Delta P_{i, d}^{j}$ is the price of $j$ th trade (ordered by time) of bond $\mathrm{i}$ at day $\mathrm{d}$. In each quarter, we aggregate the bond-level Roll measure into a fund-level Roll measure by taking share-weighted averages using the fund's bond portfolio holding shares of each bond.

Illiquidity (Bid-Ask). We use TRACE transaction data to calculate various daily liquidity measure for each bonds. We then take the within-quarter average of daily measures to get quarterly liquidity measure. Bid-ask is the difference between weighted average dealer ask prices and weighted average dealer bid prices. The weights are par volume of trades. The bid-ask measure at the fundlevel is calculated similarly to the Roll measure, as the share-weighted average of bid-ask for each corporate bond held by a given fund.

\footnotetext{
${ }^{18}$ To ensure that the dataset is survivorship-bias-free, we include funds that are inactive by the time of our data pull. Additional details on Morningstar Direct are at: https:/ /www.morningstar.com/products/direct.

${ }^{19} \mathrm{As}$ it is also standard practice in the literature, fund flows are winsorized at the $1 \%$ and $99 \%$ percentiles to mitigate the influence of outliers.
} 
Illiquidity (Ratings). Average rating of the bond holdings of the mutual fund, expressed in quarters. The ratings measure at the fund-level is calculated similarly as the Roll measure, as the share-weighted average of ratings for each corporate bond held by a given fund.

Vulnerability to Fire-Sale Spillovers. We use data on portfolio holdings to construct estimates of the effect of 100 basis points increase in fund family $j$ 's fund flow-driven fire-sale pressure on $i^{\prime} s$ current flows, $b_{i j}$. Given these estimates and an assumption for the attenuation factor $a$ (set as 0.9), we calculate a fund $i$ 's vulnerability following Falato, Hortacsu, Li, and Shin (2019), as:

$$
\text { Vulnerability }_{i}=\frac{1}{n} \sum_{s=1}^{\infty} \sum_{j=1}^{n} a^{s} b_{i j}^{s}
$$

Maturity. Average maturity of the bond holdings of the mutual fund, expressed in quarters.

Age. Fund age, defined as the number of years since fund inception.

COVID-19 Sector Exposure. Calculated for each fund at the beginning of the sample period (as of 2018Q4) by taking the sum of the value of bond holdings in the following Fama-French 49 industries, which were most severely impacted (see Fahlenbrach, Rageth and Stulz (2020) for supporting evidence): Entertainment, Construction, Automobiles and trucks, Aircraft, Ships, Personal services, Business services, Transportation, Wholesale, Retail, and Restaurants, hotels and motels. Exposure is measured based on the value of the holdings in these exposed sectors relative to total bond portfolio holdings of a given fund.

Expense ratio (\%) is the fund's expense ratio in the most recent fiscal year, defined as the total investment that the shareholders pay for the fund's operating expenses (including 12b1 fees).

Fund Size (log\$Million) is the natural log of total net assets.

Fund Age is the number of years since fund inception.

Policy Impact Variables:

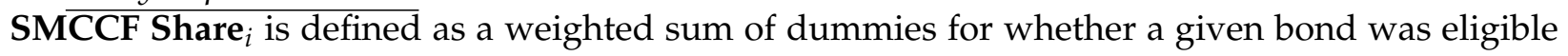
to be purchased by the SMCCF, with weights calculated based on the asset allocation of a given fund. Specifically, we start with each security with information on holdings as of February 2020 and combine it with eligibility information from the term sheet of the SMCCF to construct this measure for each fund by taking the sum over the fund's securities holdings of the percentage portfolio share holdings of each eligible security. The eligibility criteria are: maturity of under 5 years, domiciled in the US, not an insured depository institution, and rated investment grade as of March 22, 2020 and not lower than BB+ afterwards ("fallen angels").

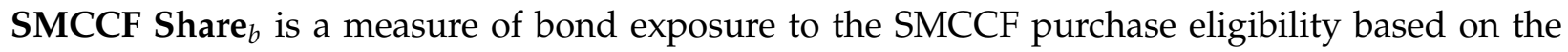
exposure of the funds that hold the outstanding bonds of a given issuer. Specifically, we construct this measure for each fund by taking the sum over the fund's securities holdings of the percentage portfolio share holdings of each eligible security. Next, we combine this measure and historical information on all the bond issues by a given issuer from FISD to rank securities based on issuerlevel average exposure to the SMCCF purchase eligibility, which is calculated as the average across outstanding issues of the fund-level measure across all outstanding issues and holders for any given issuer.

Peer SMCCF Share $i$ is defined as a weighted sum of peers' exposure to the SMCCF purchase eligibility, with weights calculated based on the asset allocation of a given fund. Specifically, we construct this measure for each fund by taking the weighted sum over the fund's securities holdings of the security-by-security SMCCF share, with the weights equal to the (own) funds' percentage portfolio share holding of each respective security. The security-level SMCCF share is an average of the fund-level share across all holders. 
SMCCF Treated $_{i}$ is defined as a dummy for exposure to eligible purchases that exploits the 5year maturity threshold for eligibility. For each fund, we construct the share of eligible (ineligible) bonds held as weighted sums of dummies for whether a given bond had a maturity of 5 years (6 years) and satisfied the other eligibility requirements to be purchased by the SMCCF, with weights calculated based on the asset allocation of a given fund. Specifically, we start with each security with information on holdings as of February 2020 and combine it with eligibility information from the term sheet of the SMCCF to construct this measure for each fund by taking the sum over the fund's securities holdings of the percentage portfolio share holdings of each eligible security. The dummy equals one (zero) for funds in the top quartile of exposure to eligible (ineligible) bonds. The observations for the other two intermediate quartiles are not included in this variable.

SMCCF Treated ${ }_{b}$ is a measure of bond exposure to the SMCCF purchase eligibility based on the exposure of the funds that hold the outstanding bonds of a given issuer. Specifically, we construct the share exposure measure for each fund as described above. Next, we combine these measures and historical information on all the bond issues by a given issuer from FISD to rank securities based on issuer-level average exposure to the SMCCF purchase eligibility, which is calculated as the average across outstanding issues of the fund-level measure across all outstanding issues and holders for any given issuer. Treated (control) issuers are those in the top quartile of eligible (ineligible) exposures. The observations for the other two intermediate quartiles are not included in this variable.

Peer SMCCF Treated $i$ is a measure of peer fund exposure to the SMCCF purchase eligibility. The Peer Treated dummy is an indicator that equals one (zero) for top quartile of the peer SMCCF share of eligible (ineligible) bonds. The observations for the other two intermediate quartiles are not included in this variable. Specifically, for each fund the share exposures are defined as above. We then construct the peer share measures for each fund by taking the weighted sum over the fund's securities holdings of the security-by-security SMCCF shares, with the weights equal to the (own) funds' percentage portfolio share holding of each respective security. The security-level SMCCF shares are averages of the fund-level shares across all holders. 


\section{Appendix B: Details of Estimating Equations}

This appendix provides additional details of the estimating equations for the main analysis of fund flows (Tables 2-4), the analysis of the flow-performance relation (Appendix Table A.5), and the analysis of heterogeneity by fund sector exposure (Table 5).

The specifications for these analyses are defined as follows:

Analysis of Fund Flows (Tables 2-4):

To provide a formal assessment of fund fragility in the COVID-19 crisis using regression analysis, we examine the following main relation:

$$
\text { Flows }_{i, t}=\alpha+\beta \times \text { Crisis }_{t}+\gamma \times X_{i, t-1}+\eta_{i}+\lambda_{t}+v_{i, t}
$$

where the outcome variable, Flows $i, t$, is primarily the daily fund's net flows for fund $i$ in day $t$, and the main variable of interest, Crisis $_{t}$, is an indicator that equals one in the crisis period. We include data from January 1, 2019 to April 17, 2020 for all the domestic corporate bond funds, and set Crisis to one starting from February 1, 2020. To better understand the evolution of flows during the crisis, we also consider a second specification with a finer set of indicators for subperiods within the crisis: a Buildup indicator for days in February 2020, an Outbreak indicator for the March 1, 2020 to March 13, 2020 period, a Peak indicator for days after the national emergency declaration on March 13, 2020 till the first Fed announcement on March 23, a First Response indicator for the March 23, 2020 to April 9, 2020 period, and a Second Response indicator for days after April 9, 2020. $X_{i, t-1}$ is a vector of controls for standard fund characteristics, which include fund size.

In estimating equation (1), we address unobserved heterogeneity by including for all tests a specification that controls for the full set of fund-specific dummies, $\eta_{i}$. The inclusion of fund fixed effects ensures that the parameter of interest, $\beta$, which represents the impact of the COVID-19 shock on fund flows, is estimated only from within-fund time-series variation. To address other contemporaneous common shocks, which are unrelated to the COVID-19 crisis and could be a potential confound for our estimates, in all the tests we include a full set of month-specific dummies, $\lambda_{t} .{ }^{20}$ The inclusion of month effects ensure that $\beta$ is estimated from within-month variation - i.e., it reflects the impact of the COVID-19 crisis period for each month in 2020 relative to the same month in 2019. The idiosyncratic error term, $v_{i, t}$, is assumed to be correlated within fund and potentially heteroskedastic (Petersen, 2006) and clustered standard errors are reported throughout (in parentheses).

Table 2 reports results for these two specifications in Panel A and B, respectively. Tables 3 and 4 report results for sample split analysis and matched-sample analysis of ETFs, respectively, that otherwise use the same two specifications. To ease presentation, additional coefficient estimates for the second specification's earlier phases of the crisis (i.e., Buildup and Outbreak) are reported in the appendix (Appendix Tables A.3, A.4, and A.6, respectively).

\section{Analysis of the Flow-Performance Relation (Appendix Table A.5):}

To inspect what the COVID-19 episode did to the sensitivity of outflows to bad performance, we modify our baseline specification as follows:

$$
\text { Flows }_{i, t}=\alpha+\beta_{1} \times \text { Crisis }_{t}+\beta_{2} \times \text { Crisis }_{t} \times \operatorname{Re} \text { turn }_{i t-1}+\gamma \times X_{i, t-1}+\eta_{i}+\lambda_{t}+v_{i, t}
$$

\footnotetext{
${ }^{20}$ We have experimented with including alternative time dummies, either quarter-specific or week-specific, both of which lead to only minor changes in our estimates.
} 
where the outcome variable, Flows $s_{i, t}$, is the daily fund's net flows for fund $i$ in day $t$, and the main variable of interest is the interaction of the Crisis indicator with lagged fund performance, Return. As in the main analysis, we also consider a richer specification with a finer set of interacted indicators for sub-periods within the crisis and policy response. For each of these specifications, we show estimates of the flow-performance relation for good vs. bad performance using piece-wise linear functions of positive $\left(\operatorname{Re} t u r n^{+}\right)$vs. negative $\left(\operatorname{Re} t u r n^{-}\right)$fund returns, to allow for asymmetries as in Goldstein, Jiang, and $\mathrm{Ng}$ (2017). $X_{i, t-1}$ is a vector of controls for standard fund characteristics, which include fund size as well as non-interacted lagged fund performance. The results are reported in Appendix Table A.5.

\section{Analysis of Heterogeneity by Fund Sector Exposure (Table 5):}

We enrich the baseline specification with an interaction term between the crisis indicator and a cross-sectional indicator for high fund exposure to COVID-19, which is calculated for each fund at the beginning of the sample period (as of 2018Q4) by taking the sum of the value of bond holdings in the following Fama-French 49 industries, which were most severely impacted (see Fahlenbrach, Rageth and Stulz (2020) for supporting evidence): Entertainment, Construction, Automobiles and trucks, Aircraft, Ships, Personal services, Business services, Transportation, Wholesale, Retail, and Restaurants, hotels and motels. Specifically, we use the following regression specification:

$$
\text { Flows }_{i, t}=\alpha+\beta_{1} \times \text { Crisis }_{t}+\beta_{2} \times \text { Crisis }_{t} \times \text { High Exposure Fund } i+\gamma \times X_{i, t-1}+\eta_{i}+\lambda_{t}+v_{i, t}
$$

where the outcome variable, Flows ${ }_{i, t}$, is as in the baseline the daily fund's net flows for fund $i$ in day $t$, and the main variable of interest, Crisist, is an indicator that equals one in the crisis period. To better understand the evolution of flows during the crisis, we again consider also a second specification with finer indicators for sub-periods within the crisis and policy response. The High Exposure Fund indicator equals one for funds in the top quartile of COVID-19 sector exposure and zero for those in the bottom quartile. $X_{i, t-1}$ is a vector of controls for standard fund characteristics, which include fund size as well as the non-interacted exposure variable for the specification that does not include fund effects. The main results are reported in Table 5. To ease presentation, the additional coefficient estimates for the second specification's earlier phases of the crisis (i.e., Buildup and Outbreak) are reported in the appendix (Appendix Table A.7). 


\section{Appendix C: Details of Additional Graphical and Robustness Analysis}

This appendix provides additional details of the results reported in the appendix tables and figures.

Motivating Evidence:

Appendix Figure A.1 shows that spreads for both investment-grade and high-yield rated corporate bonds increased dramatically starting from early March and peaked on March 23, when the Federal Reserve announced unprecedented direct interventions in the market via direct purchases of investment-grade corporate bonds by its Primary Market Corporate Credit Facility (PMCCF) and Secondary Market Corporate Credit Facility (SMCCF). The market further stabilized and reversed the spike in spreads after a second announcement by the Federal Reserve on April 9 about expanding the facilities to allow for purchases of ETFs and certain recently downgraded highyield bonds. While spreads almost tripled at their peak, they did not reach their financial crisis records. That said, the size of the bond market is much larger today, with corporate bonds outstanding standing at about \$5.8T in 2019Q4 relative to \$2.9T back in 2007Q4 (based on Financial Accounts, Table L.213).

By way of additional background on the timeline of the crisis, after the initial declaration of a public health emergency on January 31, sparse reports of confirmed infections, including several cruise ships, started to appear in February and official reports of severe disruptions to everyday life and the first official death were reported in the last week of February. In the first week of March, official reports of first confirmed infection cases outside of California and Washington started to trickle in with New York announcing its first case on March 2, followed by most other states by the end of the week. In the second week of March, governors throughout the US declared states of emergency starting with Ohio on March 9 and the official tally of infections started ramping up. At the end of the week, on March 13, a national emergency at the federal level in the US was declared.

Market commentary and policy reports noted that market functioning and liquidity were severely strained. For example, the latest Federal Reserve's Financial Stability Report (May, 2020) noted that "for a time, markets were severely dislocated, with volatilities historically high and liquidity conditions severely strained."21 Haddad, Moreira, and Muir (2020) document large discounts for corporate bonds and bond ETFs relative to their CDS spreads and NAVs, respectively. Kargar, Lester, Lindsay, Liu, Weill and Zúñiga (2020) confirm the deterioration of liquidity and detail its timing for several measures of liquidity, including the bid-ask spread, which roughly tracked the movement in spreads. ${ }^{22}$

Finally, anecdotal reports in funds' quarterly earnings calls for 2020Q1 confirm that funds experienced severe stress in March and that the policy response helped to alleviate fund stress. For example, in the earnings call of Allianz, an analyst asked: "What would happen if we had a repeat of mid-March when bond markets were close, even the treasury market was struggling, and if at the same time, you had a sudden acceleration of redemptions. Because people like me thought, oh my gosh, I need to go and buy some more - some food and I need to redeem my mutual fund. How does that impact Allianz?" The CFO of Allianz, Giulio Terzariol, answered: "So I would say, when you have a situation like that, usually, you can count on the central banks to have a liquidity. I would say, no, we just went through the situation, if you want, in Q1."

\section{Additional Graphical Analysis:}

\footnotetext{
${ }^{21}$ https://www.federalreserve.gov/publications/2020-may-financial-stability-report-asset-valuation.htm

${ }^{22}$ Among the market and policy commentary on the episode, former Federal Reserve chairs Bernanke and Yellen described the corporate bond market as "under significant stress" (Bernanke and Yellen, 2020) and argued for direct policy interventions. Vissing-Jorgensen (2020) also argues for aggressive purchase programs that include riskier highyield debt.
} 
Appendix Figure A.2 provides additional evidence that the stress on bond funds during the COVID-19 crisis was truly unprecedented. Panel A shows that, on net, in mid-March more than a third of the bond funds experienced very large daily outflows, defined as outflows that correspond to the bottom $10 \%$ of the unconditional distribution of net fund flows, as it is standard in the literature (see, for example, Coval and Stafford, 2007). Over the last decade, on most days funds experienced large inflows, on net. And again the only previous stress episode was the Taper Tantrum, when less than a fifth of the funds experience large outflows. Panel B shows that outflows were not only large in the March 2020 episode, but also persistent, as more than a quarter of the bond funds experienced two consecutive days of large outflows in mid-March, a record for the last decade.

Appendix Figure A.3 repeats the graphical analysis of daily aggregate net flows by sub-group for the different types of bond funds, investment-grade funds (Panel A), high-yield funds (Panel B), and ETFs (Panel C). Stress in March was widespread across the board of the different fund types. While investment-grade funds experienced large and sustained outflows, outflows were outsized and started a bit earlier for high-yield funds.

Appendix Figure A.4 provides a complementary perspective over the measurement of fund fragility. So far we have shown that the size of outflows in the crisis was extraordinary, which is consistent with run-type investor behavior. Building on the recent tests of rational bubbles by Phillips, Shi, and Yu (2015) (see Brunnermeier, Rother, and Schnabel (2019) for a recent application and more details), we can provide stronger evidence of run-induced fragility. This approach measures fragility based on non-stationary behavior in fund flows. More specifically, the test identifies a fragility episode as the point in time at which the Augmented Dickey-Fueller (ADF) test statistic for an explosive unit-root exceeds its critical value, which signals that fund flows are on an explosive trajectory. We perform this test for each fund sequentially over expanding daily-windows starting from January 1, 2020 and plot the cumulative net fraction of funds that experience explosive flows. While flows were not on an explosive path for most funds in January, the fraction of funds that are classified as fragile based on this approach started to increase steadily in February. By March, most fund flows experienced a non-stationary episode.

\section{Additional Estimates and Robustness Analysis:}

Panels A and B of Appendix Table A.1 show that the baseline results are robust to including ETFs, indicating that their exclusion from the main analysis is not driving the results.

Panel C of Appendix Table A.1 confirms the result in Panel B of Table 6 by repeating the main regression analysis for the extended sample that includes the post-crisis months through August 2020. Over this extended period, outflows were much more muted, confirming that flows continued to rebound after April.

Appendix Table A.2 shows that the baseline results are robust to clustering standard errors at the fund rather than at the share-class level. The standard errors in this alternative specification are little changed relative to the baseline results in Table 2.

Appendix Tables A.3 and A.4 provide additional coefficient estimates for the Buildup and Outbreak dummies (not reported in the main tables to ease presentation) for the baseline analysis (Table 2, Panels B-C) and the sample split analysis (Table 3, Panels B-C), respectively.

Appendix Table A.5 shows additional analysis of the flow-performance relation (see Appendix B for specification details). The two main economic mechanisms we have highlighted, liquidity and fire-sales, both operate via the flow-performance relation, which has a long tradition in the literature at least since Chevalier and Ellison (1997). Goldstein, Jiang, and Ng (2017) show that the well-known convexity in flow-performance relation in equity funds disappears in corporate-bond funds, as they feature a concave relation. This greater sensitivity of outflows to bad performance is shown to be a result of the illiquidity of funds' assets. ${ }^{23}$ In line with the main evidence, the

\footnotetext{
${ }^{23}$ In previous research, fragility in corporate-bond funds was manifested through greater sensitivity of outflows to
} 
coefficient on the interaction of Crisis with fund performance is positive and highly statistically significant (Panel A, Column 1), indicating that there was an increased sensitivity of flows to performance in the COVID-19 crisis. The result is robust to controlling for persistence in flows by including the lagged dependent variable (Panel A, Column 2). And it is driven by greater sensitivity of flows to bad performance (Panel A, Columns 3-4), suggesting that investors responded much more strongly to negative performance of their funds when making outflows decisions in the crisis. In all, this evidence indicates that heightened sensitivity of flows to bad performance was an important way in which fragility manifested itself in the COVID-19 crisis. The result helps to highlight a source of fragility that is specific to funds. In previous research, fragility in corporate-bond funds was manifested through greater sensitivity of outflows to bad performance. Indeed, we show that investors in corporate-bond funds responded much more strongly to negative performance of their funds in the COVID-19 crisis when making outflows decisions. As investors saw that their funds are not coping well with the market stress, and realizing that a first-mover-advantage is in place, they rushed to take their money out, aggravating the stress.

Appendix Tables A.6 and A.7 provide additional coefficient estimates for the Buildup and Outbreak dummies (not reported in the main tables to ease presentation) for the matched-sample analysis of ETFs (Table 4, Panel B) and for the analysis by fund sector exposure (Table 5, Columns 3-4).

Panel A of Appendix Table A.8 shows that the fragility proxies have explanatory power even within the subsample of investment grade (IG) funds, indicating that these forces can help to explain the large outflows even among this relatively higher tier of the market. Specifically, while IG bond funds experienced cumulative outflows of about $3 \%$ relative to their net assets, on average, in the period from February to March 2020, IG funds that were illiquid and those that were vulnerable to fire-sales experienced average cumulative outflows of about $9 \%$ and $6 \%$, respectively, in the same period. The result also helps to further tie fragility down to funds, because it holds even within the sub-group of funds with relatively high-rated and, as such, ex-ante safer bonds, whose underperformance in crisis times is harder to explain with standard risk-based factors (see Haddad, Moreira, and Muir (2020)).

Panel B of Appendix Table A.8 shows that the sample split results are robust to orthogonalizing each proxy with respect to the others, suggesting that each of the proxies is indeed capturing independent variation. This robustness check addresses the concern that there is positive crosscorrelation between the three measures of fragility (pair-wise correlations in our sample are as follows: 0.02 for Illiquidity (Roll) and Fire-sale vulnerability, 0.25 for Illiquidity (Roll) and Sector exposures, and 0.07 for Fire-sale vulnerability and sector exposure). Specifically, to implement this robustness check we first run a regression of each of the three fragility proxies (illiquidity, fire-sale vulnerability and COVID-sector exposure) on the other two proxies, in turn. We then use the estimated residual from each regression to split the sample. For example, take the illiquidity proxy. We first run a regression of the proxy (Roll) on the fire-sale vulnerability and the sector exposure proxies and then split the sample into two sub-samples based on top vs. bottom quartiles of the estimated residual from this regression. By construction, the residualized illiquidity proxy is orthogonal to the fire-sale vulnerability and COVID sector exposure proxies.

bad performance. Goldstein, Jiang, and $\mathrm{Ng}$ (2017) show that the well known convexity in flow-performance relation in equity funds disappears in corporate-bond funds, as they feature a concave relation. This greater sensitivity of outflows to bad performance is shown to be a result of the illiquidity of funds' assets. 


\section{Table 1: Summary Statistics}

This table presents time distribution (Panel A) and summary statistics (Panel B) for our sample, which comprises domestic US corporate bond funds and ETFs. The data span the period January 2010-April 2020 and consists of 4,952,183 share class-day observations for 4,142 $(1,511)$ unique share classes (funds). Variable definitions are in Appendix A.

\begin{tabular}{|c|c|c|c|}
\hline \multicolumn{4}{|c|}{ Panel A: Sample Distribution, Full Sample } \\
\hline & $\begin{array}{c}\text { Obs } \\
\text { fund-day }\end{array}$ & Share Classes & Funds \\
\hline 2010 & 396,750 & 2,160 & 781 \\
\hline 2011 & 410,361 & 2,274 & 835 \\
\hline 2012 & 406,275 & 2,300 & 854 \\
\hline 2013 & 436,277 & 2,383 & 899 \\
\hline 2014 & 467,723 & 2,600 & 962 \\
\hline 2015 & 512,731 & 2,760 & 1,000 \\
\hline 2016 & 528,468 & 2,835 & 1,032 \\
\hline 2017 & 535,465 & 2,940 & 1,054 \\
\hline 2018 & 540,693 & 3,007 & 1,118 \\
\hline 2019 & 554,235 & 2,972 & 1,137 \\
\hline 2020 & 163,205 & 2,901 & 1,110 \\
\hline Tot. & $4,952,183$ & 4,142 & 1,511 \\
\hline \multicolumn{4}{|c|}{ Panel B: Summary Statistics, Crisis Sample (2019-2020) } \\
\hline & Mean & Std Dev & p95-p5 \\
\hline \multicolumn{4}{|l|}{ Main Outcomes: } \\
\hline Flows (\%) & 0.16 & 1.69 & 5.17 \\
\hline Large Outflows & 0.10 & 0.31 & 1.00 \\
\hline 2-day Large Outflows & 0.06 & 0.25 & 1.00 \\
\hline 3-day Large Outflows & 0.04 & 0.19 & 0.00 \\
\hline 2+SC Large Outflows & 0.12 & 0.32 & 1.00 \\
\hline 3+SC Large Outflows & 0.04 & 0.20 & 0.00 \\
\hline \multicolumn{4}{|l|}{ Fund Characteristics: } \\
\hline Return (\%) & 0.07 & 0.76 & 2.22 \\
\hline Fund Size (\$Mil) & 574.62 & $1,527.34$ & $3,325.14$ \\
\hline Investment-Grade Fund & 0.60 & 0.49 & 1.00 \\
\hline ETF & 0.13 & 0.34 & 1.00 \\
\hline
\end{tabular}


Table 2: Sizing Up Fragility in the COVID-19 Crisis: Analysis of Fund Flows

This table reports share class-level regressions of daily flows on an indicator variable for the COVID-19 crisis (Panel A) and indicator variables for different stages of the crisis and policy response (Panel B) and additional regressions of daily persistent and daily correlated large outflows (Panel C). The time period is 2019-2020. All specifications include controls for fund size and month. Standard errors (in parentheses) are clustered by share class, with ${ }^{* *},{ }^{* *}$, and ${ }^{*}$ denoting significance at the $1 \%, 5 \%$, and $10 \%$ level, respectively. Variable and specification details are in Appendix A-B.

\begin{tabular}{|c|c|c|c|c|}
\hline \multicolumn{5}{|c|}{ Panel A: Crisis } \\
\hline \multirow{5}{*}{ Crisis (Feb-April 2020) } & Flows (\%) & Flows (\%) & Flows (\%) & Large \\
\hline & OLS & $\mathrm{FE}$ & Bottom Decile & Outflows \\
\hline & (1) & (2) & (3) & (4) \\
\hline & $-0.25^{* * *}$ & $-0.29^{* * *}$ & $-1.39^{* * *}$ & $0.11^{* * *}$ \\
\hline & $(0.02)$ & $(0.02)$ & $(0.02)$ & $(0.00)$ \\
\hline FE & Month & Month, Fund & Month & Month \\
\hline Nobs & 619,222 & 619,222 & 619,222 & 619,222 \\
\hline $\mathrm{R}^{2}(\%)$ & 0.8 & 13.9 & 3.1 & 2.6 \\
\hline \multicolumn{5}{|c|}{ Panel B: Evolution of the Crisis and Policy Response } \\
\hline & Flows $(\%)$ & Flows $(\%)$ & Flows $(\%)$ & Large \\
\hline & OLS & $\mathrm{FE}$ & Bottom Decile & Outflows \\
\hline & (1) & (2) & (3) & $(4)$ \\
\hline \multirow[t]{2}{*}{ Peak (Mar 13-23, 2020) } & $-0.89^{* * *}$ & $-0.92^{* * *}$ & $-3.16^{* * *}$ & $0.29^{* * *}$ \\
\hline & $(0.05)$ & $(0.05)$ & $(0.07)$ & $(0.01)$ \\
\hline \multirow[t]{2}{*}{ First Response (Mar 23-Apr 9, 2020) } & $-0.52^{* * *}$ & $-0.55^{* * *}$ & $-1.97^{* * *}$ & $0.18^{* * *}$ \\
\hline & $(0.03)$ & $(0.03)$ & $(0.03)$ & $(0.01)$ \\
\hline \multirow[t]{2}{*}{ Second Response (Apr 9-17, 2020) } & $-0.08^{*}$ & $-0.11^{* *}$ & $-0.62^{* * *}$ & $0.09^{* * *}$ \\
\hline & $(0.05)$ & $(0.05)$ & $(0.07)$ & $(0.01)$ \\
\hline FE & Month & Month, Fund & Month & Month \\
\hline $\mathrm{N}$ obs & 619,222 & 619,222 & 619,222 & 619,222 \\
\hline \multirow[t]{5}{*}{$\mathrm{R}^{2}(\%)$} & 1.2 & 14.0 & 4.7 & 3.5 \\
\hline & ditional Analy & s of Large Outf & ows & \\
\hline & 2-day Large & 3-day Large & 2+SC Large & 3+SC Large \\
\hline & Outflows & Outflows & Outflows & Outflows \\
\hline & (1) & $(2)$ & (3) & $(4)$ \\
\hline \multirow[t]{2}{*}{ Peak (Mar 13-23, 2020) } & $0.22^{* * *}$ & $0.15^{* * *}$ & $0.38^{* * *}$ & $0.28^{* * *}$ \\
\hline & $(0.01)$ & $(0.01)$ & $(0.01)$ & $(0.01)$ \\
\hline \multirow[t]{2}{*}{ First Response (Mar 23-Apr 9, 2020) } & $0.15^{* * *}$ & $0.09^{* * *}$ & $0.25^{* * *}$ & $0.18^{* * *}$ \\
\hline & $(0.00)$ & $(0.00)$ & $(0.01)$ & $(0.00)$ \\
\hline \multirow[t]{2}{*}{ Second Response (Apr 9-17, 2020) } & $0.08^{* * *}$ & $0.04^{* * *}$ & $0.15^{* * *}$ & $0.08^{* * *}$ \\
\hline & $(0.01)$ & $(0.00)$ & $(0.01)$ & $(0.00)$ \\
\hline FE & Month & Month & Month & Month \\
\hline Nobs & 619,222 & 619,222 & 619,222 & 619,222 \\
\hline $\mathrm{R}^{2}(\%)$ & 3.2 & 2.4 & 5.5 & 7.2 \\
\hline
\end{tabular}


Table 3: Sources of Fragility in the COVID-19 Crisis: Heterogeneity Analysis

This table reports results of sample split analysis of daily flows regressed on an indicator variable for the COVID-19 crisis (Panel A) and indicator variables for different stages of the crisis and policy response (Panels B-C). Sample splits are by fund liquidity based on Roll, bid-ask spreads, and bond ratings, and by fund vulnerability to fire-sale spillovers, age, and maturity. The time period is 2019-2020. All specifications include controls for fund size and month. Standard errors (in parentheses) are clustered by share class, with $* * *, * *$, and ${ }^{*}$ denoting significance at the $1 \%, 5 \%$, and $10 \%$ level, respectively. Variable and specification details are in Appendix A-B.

\begin{tabular}{|c|c|c|c|c|c|c|}
\hline \multicolumn{7}{|c|}{ Panel A: Crisis } \\
\hline & \multicolumn{2}{|c|}{ Roll } & \multicolumn{2}{|c|}{ Bid-Ask } & \multicolumn{2}{|c|}{ Vulnerability } \\
\hline & $\begin{array}{l}\text { Illiq } \\
(1)\end{array}$ & $\begin{array}{l}\text { Liq } \\
\text { (2) }\end{array}$ & $\begin{array}{l}\text { Illiq } \\
\text { (3) }\end{array}$ & $\begin{array}{l}\mathrm{Liq} \\
(4)\end{array}$ & $\begin{array}{l}\text { Low } \\
(5)\end{array}$ & $\begin{array}{l}\text { High } \\
\text { (6) }\end{array}$ \\
\hline Crisis (Feb-April 2020) & $\begin{array}{c}-0.36^{* * *} \\
(0.05)\end{array}$ & $\begin{array}{l}-0.10 \\
(0.06)\end{array}$ & $\begin{array}{c}-0.40^{* * *} \\
(0.05)\end{array}$ & $\begin{array}{l}-0.06 \\
(0.06)\end{array}$ & $\begin{array}{c}-0.19^{* * *} \\
(0.04)\end{array}$ & $\begin{array}{c}-0.32^{* * *} \\
(0.04)\end{array}$ \\
\hline Month, Fund FE & Yes & Yes & Yes & Yes & Yes & Yes \\
\hline $\mathrm{N}$ obs & 86,954 & 87,134 & 88,600 & 86,599 & 165,403 & 177,561 \\
\hline $\mathrm{R}^{2}(\%)$ & 12.9 & 7.4 & 12.0 & 6.3 & 9.8 & 13.6 \\
\hline \multicolumn{7}{|c|}{ Panel B: Evolution of the Crisis and Policy Response by Fund Liquidity } \\
\hline & \multicolumn{2}{|c|}{ Roll } & \multicolumn{2}{|c|}{ Bid-Ask } & \multicolumn{2}{|c|}{ Ratings } \\
\hline & $\begin{array}{l}\text { Illiq } \\
(1)\end{array}$ & $\begin{array}{l}\text { Liq } \\
(2)\end{array}$ & $\begin{array}{l}\text { Illiq } \\
\text { (3) }\end{array}$ & $\begin{array}{l}\text { Liq } \\
(4)\end{array}$ & $\begin{array}{l}\text { Illiq } \\
\text { (5) }\end{array}$ & $\begin{array}{l}\text { Liq } \\
(6)\end{array}$ \\
\hline Peak (Mar 13-Mar 23, 2020) & $\begin{array}{c}-1.28^{* * *} \\
(0.10)\end{array}$ & $\begin{array}{c}-0.67^{* * *} \\
(0.16)\end{array}$ & $\begin{array}{c}-1.35^{* * *} \\
(0.11)\end{array}$ & $\begin{array}{c}-0.45^{* * *} \\
(0.15)\end{array}$ & $\begin{array}{c}-1.72^{* * *} \\
(0.10)\end{array}$ & $\begin{array}{l}-0.02 \\
(0.16)\end{array}$ \\
\hline First Response (Mar 23-Apr 9, 2020) & $\begin{array}{c}-0.55^{* * *} \\
(0.06)\end{array}$ & $\begin{array}{c}-0.57^{* * *} \\
(0.09)\end{array}$ & $\begin{array}{c}-0.52^{* * *} \\
(0.07)\end{array}$ & $\begin{array}{c}-0.53^{* * *} \\
(0.08)\end{array}$ & $\begin{array}{c}-0.41^{* * *} \\
(0.07)\end{array}$ & $\begin{array}{c}-0.28^{* * *} \\
(0.10)\end{array}$ \\
\hline Second Response (Apr 9-17, 2020) & $\begin{array}{l}-0.04 \\
(0.10)\end{array}$ & $\begin{array}{c}0.05 \\
(0.13)\end{array}$ & $\begin{array}{c}0.07 \\
(0.12)\end{array}$ & $\begin{array}{c}-0.02 \\
(0.13)\end{array}$ & $\begin{array}{c}0.36^{* * *} \\
(0.13)\end{array}$ & $\begin{array}{c}0.06 \\
(0.16)\end{array}$ \\
\hline Month, Fund FE & Yes & Yes & Yes & Yes & Yes & Yes \\
\hline $\mathrm{N}$ obs & 86,954 & 87,134 & 88,600 & 86,599 & 100,923 & 86,795 \\
\hline $\mathrm{R}^{2}(\%)$ & 14.2 & 8.6 & 12.4 & 7.4 & 14.3 & 8.0 \\
\hline \multicolumn{7}{|c|}{ Panel C: Evolution of the Crisis and Policy Response by Fund Fire-Sale Vulnerability } \\
\hline & \multicolumn{2}{|c|}{ Vulnerability } & \multicolumn{2}{|c|}{ Age } & \multicolumn{2}{|c|}{ Maturity } \\
\hline & $\begin{array}{l}\text { Low } \\
(1)\end{array}$ & $\begin{array}{l}\text { High } \\
(2)\end{array}$ & $\begin{array}{l}\text { Young } \\
\text { (3) }\end{array}$ & $\begin{array}{c}\text { Old } \\
(4)\end{array}$ & $\begin{array}{l}\text { Short } \\
(5)\end{array}$ & $\begin{array}{l}\text { Long } \\
\text { (6) }\end{array}$ \\
\hline Peak (Mar 13-23, 2020) & $\begin{array}{c}-0.65^{* * *} \\
(0.06)\end{array}$ & $\begin{array}{c}-1.09^{* * *} \\
(0.08)\end{array}$ & $\begin{array}{c}-0.79^{* * *} \\
(0.11)\end{array}$ & $\begin{array}{c}-0.64^{* * *} \\
(0.07)\end{array}$ & $\begin{array}{c}-0.56^{* *} \\
(0.24)\end{array}$ & $\begin{array}{c}-0.75^{* * *} \\
(0.16)\end{array}$ \\
\hline First Response (Mar 23-Apr 9, 2020) & $\begin{array}{c}-0.54^{* * *} \\
(0.03)\end{array}$ & $\begin{array}{c}-0.58^{* * *} \\
(0.05)\end{array}$ & $\begin{array}{c}-0.54^{* * *} \\
(0.07)\end{array}$ & $\begin{array}{c}-0.31^{* * *} \\
(0.05)\end{array}$ & $\begin{array}{c}-0.59^{* * *} \\
(0.14)\end{array}$ & $\begin{array}{c}-0.59^{* * *} \\
(0.10)\end{array}$ \\
\hline Second Response (Apr 9-17, 2020) & $\begin{array}{l}-0.04 \\
(0.05)\end{array}$ & $\begin{array}{l}-0.12^{*} \\
(0.07)\end{array}$ & $\begin{array}{c}-0.22^{* *} \\
(0.10)\end{array}$ & $\begin{array}{c}0.10 \\
(0.08)\end{array}$ & $\begin{array}{c}0.13 \\
(0.18)\end{array}$ & $\begin{array}{l}-0.14 \\
(0.20)\end{array}$ \\
\hline Month, Fund FE & Yes & Yes & Yes & Yes & Yes & Yes \\
\hline N obs & 165,403 & 177,561 & 169,086 & 182,969 & 32,973 & 33,710 \\
\hline $\mathrm{R}^{2}(\%)$ & 13.6 & 13.9 & 15.1 & 9.7 & 6.4 & 10.3 \\
\hline
\end{tabular}




\section{Table 4: Sources of Fragility in the COVID-19 Crisis: Analysis of ETFs}

This table shows results of a matched-sample analysis of ETF flows. To implement the estimator, we use a methodology analogous to long-run event studies and for each ETF-day construct a "benchmark" flow variable, $\overline{\text { Flows }}_{-i, t}$, for a matched portfolio of bond funds. The covariates used for matching are size, age, and performance. We then repeat the baseline analysis for lows $_{i, t}-\overline{\text { Flows }}_{-i, t}$. Panel A reports results for an indicator variable for the COVID-19 crisis and Panel B reports results for indicator variables for different stages of the crisis and policy response. The time period is 2019-2020. All specifications include controls for fund size and month. Standard errors (in parentheses) are clustered by share class, with ***,**, and * denoting significance at the $1 \%, 5 \%$, and $10 \%$ level, respectively. Variable and specification details are in Appendix A-B.

\begin{tabular}{|c|c|c|c|c|}
\hline \multicolumn{5}{|c|}{ Panel A: Crisis } \\
\hline & Flows (\%) & Large & 2-Day Large & 2+SC Large \\
\hline & $\mathrm{FE}$ & Outflows & Outflows & Outflows \\
\hline & (1) & (2) & (3) & (4) \\
\hline \multirow[t]{2}{*}{ Crisis (Feb-April 2020) } & $0.16^{* * *}$ & $-0.07^{* * *}$ & $-0.05^{* * *}$ & $-0.16^{* * *}$ \\
\hline & $(0.06)$ & $(0.01)$ & $(0.01)$ & $(0.00)$ \\
\hline FE & Month, Fund & Month, Fund & Month, Fund & Month, Fund \\
\hline N obs & 93,654 & 93,654 & 93,654 & 93,654 \\
\hline $\mathrm{R}^{2}(\%)$ & 10.6 & 10.2 & 7.9 & 33.0 \\
\hline \multicolumn{5}{|c|}{ Panel B: Evolution of the Crisis and Policy Response } \\
\hline & Flows (\%) & Large & 2-Day Large & 2+SC Large \\
\hline & $\mathrm{FE}$ & Outflows & Outflows & Outflows \\
\hline & (1) & $(2)$ & (3) & $(4)$ \\
\hline \multirow[t]{2}{*}{ Peak (Mar 13-23, 2020) } & -0.10 & $-0.06^{* * *}$ & $-0.04^{* * *}$ & $-0.37^{* * *}$ \\
\hline & $(0.13)$ & $(0.02)$ & $(0.02)$ & $(0.00)$ \\
\hline \multirow[t]{2}{*}{ First Response (Mar 23-Apr 9, 2020) } & 0.08 & $-0.10^{* * *}$ & $-0.08^{* * *}$ & $-0.25^{* * *}$ \\
\hline & $(0.09)$ & $(0.01)$ & $(0.01)$ & $(0.00)$ \\
\hline \multirow[t]{2}{*}{ Second Response (Apr 9-17, 2020) } & $0.36^{* *}$ & $-0.10^{* * *}$ & $-0.08^{* * *}$ & $-0.14^{* * *}$ \\
\hline & $(0.15)$ & $(0.01)$ & $(0.01)$ & $(0.00)$ \\
\hline FE & Month, Fund & Month, Fund & Month, Fund & Month, Fund \\
\hline $\mathrm{N}$ obs & 93,654 & 93,654 & 93,654 & 93,654 \\
\hline $\mathrm{R}^{2}(\%)$ & 9.9 & 10.1 & 6.5 & 35.9 \\
\hline
\end{tabular}


Table 5: Sources of Fragility in the COVID-19 Crisis: Analysis by Fund Sector Exposure

This table reports share class-level regressions of daily flows on an indicator for fund COVID-19 sector exposure and its interaction with an indicator variable for the COVID-19 crisis (Columns 1-2) and indicator variables for different stages of the crisis and policy response (Columns 3-4). The COVID-19 sector exposure is based on holdings of the following Fama-French 49 industries: Entertainment, Construction, Automobiles and trucks, Aircraft, Ships, Personal services, Business services, Transportation, Wholesale, Retail, and Restaurants, hotels and motels. The time period is 2019-2020. All specifications include controls for fund size and month. Standard errors (in parentheses) are clustered by share class, with ${ }^{* * *},{ }^{* *}$, and * denoting significance at the $1 \%, 5 \%$, and $10 \%$ level, respectively. Variable and specification details are in Appendix A-B.

\begin{tabular}{|c|c|c|c|c|}
\hline \multicolumn{5}{|c|}{ Panel A: Analysis by Fund Sector Exposure } \\
\hline & \multicolumn{2}{|c|}{ Crisis } & \multicolumn{2}{|c|}{ Crisis and Policy Response } \\
\hline & $\begin{array}{l}\text { OLS } \\
(1)\end{array}$ & $\begin{array}{l}\mathrm{FE} \\
(2)\end{array}$ & $\begin{array}{l}\text { OLS } \\
\text { (3) }\end{array}$ & $\begin{array}{l}\text { FE } \\
(4)\end{array}$ \\
\hline Crisis (Feb-April 2020) & $\begin{array}{c}-0.15^{* * *} \\
(0.05)\end{array}$ & $\begin{array}{c}-0.19^{* * *} \\
(0.05)\end{array}$ & & \\
\hline Peak (Mar 13-23, 2020) & & & $\begin{array}{c}-0.78^{* * *} \\
(0.12)\end{array}$ & $\begin{array}{c}-0.81^{* * *} \\
(0.12)\end{array}$ \\
\hline First Response (Mar 23-Apr 9, 2020) & & & $\begin{array}{c}-0.51^{* * *} \\
(0.07)\end{array}$ & $\begin{array}{c}-0.53^{* * *} \\
(0.07)\end{array}$ \\
\hline Second Response (Apr 9-17, 2020) & & & $\begin{array}{l}-0.13 \\
(0.13)\end{array}$ & $\begin{array}{l}-0.16 \\
(0.13)\end{array}$ \\
\hline High Exposure Fund & $\begin{array}{l}-0.01 \\
(0.03)\end{array}$ & & $\begin{array}{l}-0.01 \\
(0.03)\end{array}$ & \\
\hline High Exposure Fund ${ }^{*}$ Crisis & $\begin{array}{c}-0.27^{* * *} \\
(0.06)\end{array}$ & $\begin{array}{c}-0.22^{* * *} \\
(0.06)\end{array}$ & & \\
\hline High Exposure Fund*Peak & & & $\begin{array}{c}-0.76^{* * *} \\
(0.18)\end{array}$ & $\begin{array}{c}-0.71^{* * *} \\
(0.18)\end{array}$ \\
\hline High Exposure Fund*First Response & & & $\begin{array}{l}-0.01 \\
(0.10)\end{array}$ & $\begin{array}{c}0.05 \\
(0.10)\end{array}$ \\
\hline High Exposure Fund*Second Response & & & $\begin{array}{l}0.32^{*} \\
(0.17)\end{array}$ & $\begin{array}{c}0.37^{* *} \\
(0.17)\end{array}$ \\
\hline Month FE & Yes & Yes & Yes & Yes \\
\hline Fund FE & No & Yes & No & Yes \\
\hline N obs & 183,331 & 183,331 & 183,331 & 183,331 \\
\hline $\mathrm{R}^{2}(\%)$ & 1.2 & 11.5 & 2.1 & 12.0 \\
\hline
\end{tabular}


Table 6: Sources of Fragility in the COVID-19 Crisis: Implications for Cumulative Flows

This table reports an Oaxaca-Blinder style regression-based quantification of the contribution of different sources of fragility to cumulative outflows in the COVID-19 crisis. For each of the three sources of fragility (illiquidity, fire-sale vulnerability and sector exposure), we use the following approach. For example, take illiquidity. We split the sample into two sub-samples based on top vs. bottom quartiles of the illiquidity proxy (Roll). We regress cumulative fund flows (relative to net assets) on the crisis dummy as well as fund controls (size) for liquid funds. We store the estimated coefficients and use them to predict cumulative flows for illiquid funds, which provides the counterfactual of flows for illiquid funds if they were liquid. Finally, we take the difference between cumulative flows and predicted cumulative flows for illiquid funds, which is our measure of the impact of COVID-19 on cumulative flows that can be attributed to illiquidity. In Panel A, we report the \% share explained, which is the ratio of the difference between cumulative flows and predicted cumulative flows divided by cumulative flows for illiquid funds. For reference, we also report in the bottom panels cumulative flows based on a fragility factor that is constructed using principal component analysis to aggegate across the three proxies (with factor loadings 0.4207, 0.1146, and 0.4313, respectively) and cumulative flows in the Taper Tantrum. In Panel B, we report cumulative flows in the post-crisis period through August 2020. Variable definitions are in Appendix A.

Panel A: Cumulative Flows in the Crisis

\section{Feb-Mar, 2020}

Cumulative Flows

Cumulative Flows, Illiquid Funds (Roll)

Cumulative Flows, Fire-Sale Vulnerable Funds

Cumulative Flows, High Sector Exposure Funds

Share Explained (Fund Liquidity (Roll))

Share Explained (Fund Fire-Sale Vulnerability)

Share Explained (Fund Sector Exposure)

Aggregating Across Proxies: Fragility Factor

Cumulative Flows

Historical Comparison: Taper Tantrum

Cumulative Flows

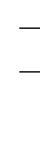

Cumulative Flows
Feb-Mar, 2020

May-Jun, 2013

Panel B: Cumulative Flows Post-Crisis
(1)

$$
-10.2 \%
$$$$
-18.7 \%
$$$$
-16.5 \%
$$

$40.1 \%$

$55.7 \%$

$63.8 \%$

$-23.2 \%$

$-2.2 \%$

$-2.4 \%$

Mar-Apr, 2020

$-6.7 \%$

$-14.8 \%$

$-11.4 \%$

$-16.6 \%$

$27.6 \%$

$37.3 \%$

$55.4 \%$

Mar-Apr, 2020

$-17.7 \%$

Jun-Jul, 2013

Apr-Aug, 2020

Feb-Aug, 2020

$9.3 \%$

$1.4 \%$ 
Table 7: The Fragility Channel of SMCCF: Impact of Fed Purchase Eligibility

This table reports regressions of cumulative fund flows (Panels A and C) and bond market outcomes (Panel B) on measures of fund and bond exposure to the SMCCF purchase eligibility. Panel A reports results for cumulative percentage flows and large outflows in the post-SMCCF period from April 10 through August 31, 2020. The SMCCF Share is a fund-level weighted sum of dummies for whether a given bond was eligible to be purchased by the SMCCF, with weights calculated based on the asset allocation of a given fund (percentage portfolio share holdings of each eligible security as of February 2020). The eligibility criteria are from the term sheet of the SMCCF. All specifications include controls for fund size. Panel B reports results for primary market bond issuance volumes and spreads and secondary spreads in the postSMCCF period on a measure of bond exposure to the SMCCF purchase eligibility based on the exposure of the funds that hold the outstanding bonds of a given issuer. All specifications include controls for bond size, rating, maturity, and SMCCF eligibility. Panel C reports regressions of cumulative fund flows and large outflows in the post-SMCCF period on a measure of peer fund exposure to the SMCCF purchase eligibility. The Peer SMCCF Share is a weighted sum of peers' exposure to the SMCCF purchase eligibility, with weights calculated based on the asset allocation of a given fund. All specifications include controls for fund size and SMCCF exposure. To ease interpretation, the explanatory variables are expressed in standard deviation units. Standard errors are in parentheses, with ${ }^{* * *}, * *$, and ${ }^{*}$ denoting significance at the $1 \%, 5 \%$, and $10 \%$ level, respectively. Variable definitions are in Appendix A.

\begin{tabular}{|c|c|c|c|c|c|c|}
\hline \multicolumn{7}{|c|}{ Panel A: Fund Impact } \\
\hline & \multicolumn{3}{|c|}{ Cumulative Flows (\%) } & \multicolumn{3}{|c|}{ Large Outflows } \\
\hline & $\begin{array}{l}\text { All } \\
(1)\end{array}$ & $\begin{array}{l}\text { Illiquid } \\
\text { (2) }\end{array}$ & $\begin{array}{l}\text { Vulnerable } \\
\text { (3) }\end{array}$ & $\begin{array}{l}\text { All } \\
(4)\end{array}$ & $\begin{array}{l}\text { Illiquid } \\
\text { (5) }\end{array}$ & $\begin{array}{c}\text { Vulnerable } \\
\text { (6) }\end{array}$ \\
\hline SMCCF Share $_{i}$ & $\begin{array}{c}2.76^{* * *} \\
(0.82)\end{array}$ & $\begin{array}{c}5.39^{* * *} \\
(1.16)\end{array}$ & $\begin{array}{c}7.69^{* * * *} \\
(2.69)\end{array}$ & $\begin{array}{c}-0.02^{* * *} \\
(0.00)\end{array}$ & $\begin{array}{c}-0.02^{* * *} \\
(0.01)\end{array}$ & $\begin{array}{c}-0.04^{* * *} \\
(0.01)\end{array}$ \\
\hline N obs. & 2,441 & 324 & 346 & 2,441 & 324 & 346 \\
\hline $\mathrm{R}^{2}(\%)$ & 0.70 & 1.87 & 2.45 & 2.27 & 4.07 & 10.20 \\
\hline Mean LHS & 9.33 & -2.32 & 3.62 & 0.10 & 0.13 & 0.12 \\
\hline \multicolumn{7}{|c|}{ Panel B: Bond Spillover } \\
\hline & \multicolumn{3}{|c|}{ All } & \multicolumn{3}{|c|}{ Illiquid Holders } \\
\hline & $\begin{array}{l}\text { Issuance } \\
\text { (1) }\end{array}$ & $\begin{array}{l}\text { Pr. Spreads } \\
\text { (2) }\end{array}$ & $\begin{array}{l}\text { Sec. Spreads } \\
\text { (3) }\end{array}$ & $\begin{array}{c}\text { Issuance } \\
(4)\end{array}$ & $\begin{array}{l}\text { Pr. Spreads } \\
\text { (5) }\end{array}$ & $\begin{array}{c}\text { Sec. Spreads } \\
\text { (6) }\end{array}$ \\
\hline SMCCF Share $_{b}$ & $\begin{array}{c}0.46^{* * *} \\
(0.05)\end{array}$ & $\begin{array}{c}-0.16^{* * *} \\
(0.04)\end{array}$ & $\begin{array}{c}-0.10^{* * *} \\
(0.02)\end{array}$ & $\begin{array}{c}0.48^{* * *} \\
(0.09)\end{array}$ & $\begin{array}{c}-0.39^{* * *} \\
(0.09)\end{array}$ & $\begin{array}{c}-0.22^{* * *} \\
(0.03)\end{array}$ \\
\hline $\mathrm{N}$ obs. & 116 & 483 & 5,602 & 41 & 82 & 858 \\
\hline $\mathrm{R}^{2}(\%)$ & 5.03 & 22.76 & 3.61 & 15.25 & 28.92 & 10.12 \\
\hline Mean LHS & 1.57 & 1.99 & -0.82 & 1.57 & 2.59 & -0.82 \\
\hline \multicolumn{7}{|c|}{ Panel C: Fund Spillover } \\
\hline & \multicolumn{3}{|c|}{ Cumulative Flows (\%) } & \multicolumn{3}{|c|}{ Large Outflows } \\
\hline & $\begin{array}{l}\text { All } \\
(1)\end{array}$ & $\begin{array}{l}\text { Illiquid } \\
\text { (2) }\end{array}$ & $\begin{array}{l}\text { Vulnerable } \\
\text { (3) }\end{array}$ & $\begin{array}{l}\text { All } \\
(4)\end{array}$ & $\begin{array}{l}\text { Illiquid } \\
\text { (5) }\end{array}$ & $\begin{array}{c}\text { Vulnerable } \\
\text { (6) }\end{array}$ \\
\hline Peer SMCCF Share ${ }_{i}$ & $\begin{array}{c}0.12 \\
(0.97)\end{array}$ & $\begin{array}{c}0.26 \\
(1.68)\end{array}$ & $\begin{array}{c}0.44 \\
(2.34)\end{array}$ & $\begin{array}{c}-0.02^{* * *} \\
(0.00)\end{array}$ & $\begin{array}{c}-0.03^{* * *} \\
(0.01)\end{array}$ & $\begin{array}{c}-0.03^{* * *} \\
(0.01)\end{array}$ \\
\hline N obs. & 2,441 & 324 & 346 & 2,441 & 324 & 346 \\
\hline$R^{2}(\%)$ & 0.94 & 1.86 & 5.44 & 2.42 & 6.63 & 11.30 \\
\hline
\end{tabular}


Table 8: Identifying the Fragility Channel of SMCCF: Maturity Threshold for Eligibility

This table reports regressions of cumulative fund flows (Panels A and C) and bond market outcomes (Panel B) on refined measures of fund and bond exposure to the SMCCF purchase exposure. Panel A reports results for cumulative percentage flows and large outflows in the post-SMCCF period from April 10 through August 31, 2020. SMCCF Treated is a dummy for exposure to eligible purchases that exploits the 5-year maturity threshold for eligibility. For each fund, we construct the share of eligible (ineligible) bonds held as weighted sums of dummies for whether a given bond had a maturity of 5 years (6 years) and satisfied the other eligibility requirements to be purchased by the SMCCF, with weights calculated based on the asset allocation of a given fund. All specifications include controls for fund size. Panel B reports results for primary market bond issuance volumes and spreads and secondary spreads in the post-SMCCF period on a measure of bond exposure to the SMCCF purchase eligibility based on the exposure of the funds that hold the outstanding bonds of a given issuer. All specifications include controls for bond size, rating, maturity, and SMCCF eligibility. Panel C reports regressions of cumulative fund flows and large outflows in the post-SMCCF period on a measure of peer fund exposure to the SMCCF purchase eligibility. The Peer Treated dummy is an indicator that equals one (zero) for top quartile of the peer SMCCF share of eligible (ineligible) bonds. All specifications include controls for fund size and SMCCF exposure. Standard errors are in parentheses, with ${ }^{* * *},{ }^{* *}$, and ${ }^{*}$ denoting significance at the $1 \%, 5 \%$, and $10 \%$ level, respectively. Variable definitions are in Appendix A.

\begin{tabular}{|c|c|c|c|c|c|c|}
\hline \multicolumn{7}{|c|}{ Panel A: Fund Impact } \\
\hline & \multicolumn{3}{|c|}{ Cumulative Flows (\%) } & \multicolumn{3}{|c|}{ Large Outflows } \\
\hline & $\begin{array}{l}\text { All } \\
\text { (1) }\end{array}$ & $\begin{array}{l}\text { Illiquid } \\
\text { (2) }\end{array}$ & $\begin{array}{l}\text { Vulnerable } \\
\text { (3) }\end{array}$ & $\begin{array}{l}\text { All } \\
(4)\end{array}$ & $\begin{array}{l}\text { Illiquid } \\
\text { (5) }\end{array}$ & $\begin{array}{l}\text { Vulnerable } \\
\text { (6) }\end{array}$ \\
\hline SMCCF Treated $_{i}$ & $\begin{array}{c}7.35^{* *} \\
(3.33)\end{array}$ & $\begin{array}{c}7.85^{* *} \\
(3.75)\end{array}$ & $\begin{array}{c}7.47^{* *} \\
(3.33)\end{array}$ & $\begin{array}{c}-0.04^{* * *} \\
(0.01)\end{array}$ & $\begin{array}{c}-0.05^{* * *} \\
(0.02)\end{array}$ & $\begin{array}{c}-0.04^{* * *} \\
(0.01)\end{array}$ \\
\hline N obs. & 1,412 & 254 & 215 & 1,412 & 254 & 215 \\
\hline $\mathrm{R}^{2}(\%)$ & 0.40 & 4.01 & 0.66 & 2.61 & 9.57 & 14.41 \\
\hline \multicolumn{7}{|c|}{ Panel B: Bond Spillover } \\
\hline & \multicolumn{3}{|c|}{ All } & \multicolumn{3}{|c|}{ Illiquid Holders } \\
\hline & $\begin{array}{c}\text { Issuance } \\
\text { (1) }\end{array}$ & $\begin{array}{l}\text { Pr. Spreads } \\
\text { (2) }\end{array}$ & $\begin{array}{l}\text { Sec. Spreads } \\
\text { (3) }\end{array}$ & $\begin{array}{c}\text { Issuance } \\
(4)\end{array}$ & $\begin{array}{l}\text { Pr. Spreads } \\
\text { (5) }\end{array}$ & $\begin{array}{c}\text { Sec. Spreads } \\
\text { (6) }\end{array}$ \\
\hline $\mathrm{SMCCF}_{\text {Treated }}$ & $\begin{array}{c}0.30^{* * *} \\
(0.04)\end{array}$ & $\begin{array}{c}-0.09^{* *} \\
(0.04)\end{array}$ & $\begin{array}{c}-0.16^{* * *} \\
(0.04)\end{array}$ & $\begin{array}{c}0.56^{* * *} \\
(0.14)\end{array}$ & $\begin{array}{c}-0.25^{* * *} \\
(0.08)\end{array}$ & $\begin{array}{c}-0.28^{* *} \\
(0.11)\end{array}$ \\
\hline N obs. & 116 & 483 & 1,669 & 41 & 82 & 341 \\
\hline $\mathrm{R}^{2}(\%)$ & 4.71 & 16.32 & 4.72 & 15.61 & 23.08 & 13.28 \\
\hline \multicolumn{7}{|c|}{ Panel C: Fund Spillover } \\
\hline & \multicolumn{3}{|c|}{ Cumulative Flows (\%) } & \multicolumn{3}{|c|}{ Large Outflows } \\
\hline & $\begin{array}{l}\text { All } \\
\text { (1) }\end{array}$ & $\begin{array}{l}\text { Illiquid } \\
\text { (2) }\end{array}$ & $\begin{array}{l}\text { Vulnerable } \\
\text { (3) }\end{array}$ & $\begin{array}{l}\text { All } \\
(4)\end{array}$ & $\begin{array}{l}\text { Illiquid } \\
\text { (5) }\end{array}$ & $\begin{array}{c}\text { Vulnerable } \\
\text { (6) }\end{array}$ \\
\hline Peer SMCCF Treated $i$ & $\begin{array}{c}4.18 \\
(3.16)\end{array}$ & $\begin{array}{c}5.27 \\
(4.94)\end{array}$ & $\begin{array}{c}4.31 \\
(5.89)\end{array}$ & $\begin{array}{c}-0.02^{* * *} \\
(0.01)\end{array}$ & $\begin{array}{c}-0.03^{* *} \\
(0.01)\end{array}$ & $\begin{array}{c}-0.03^{* *} \\
(0.01)\end{array}$ \\
\hline N obs. & 1,413 & 222 & 195 & 1,413 & 222 & 195 \\
\hline $\mathrm{R}^{2}(\%)$ & 1.26 & 3.55 & 8.80 & 1.43 & 8.40 & 11.12 \\
\hline
\end{tabular}


Figure 1: The Growing Importance of Funds in the Corporate Bond Market

This figure plots the quarterly time-series of an estimate of the importance of corporate bond funds and ETFs. The numerator is the aggregate dollar value of net assets of bond funds and ETFs, which is calculated by aggregating over individual funds' net assets. The denominator is the aggregate dollar value of nonfinancial corporate bonds outstanding. Time period is 2010Q1 to 2019Q4. Data source: Morningstar for net assets and Flow of Funds (Federal Reserve Board Financial Accounts, Z.1) for bonds outstanding.

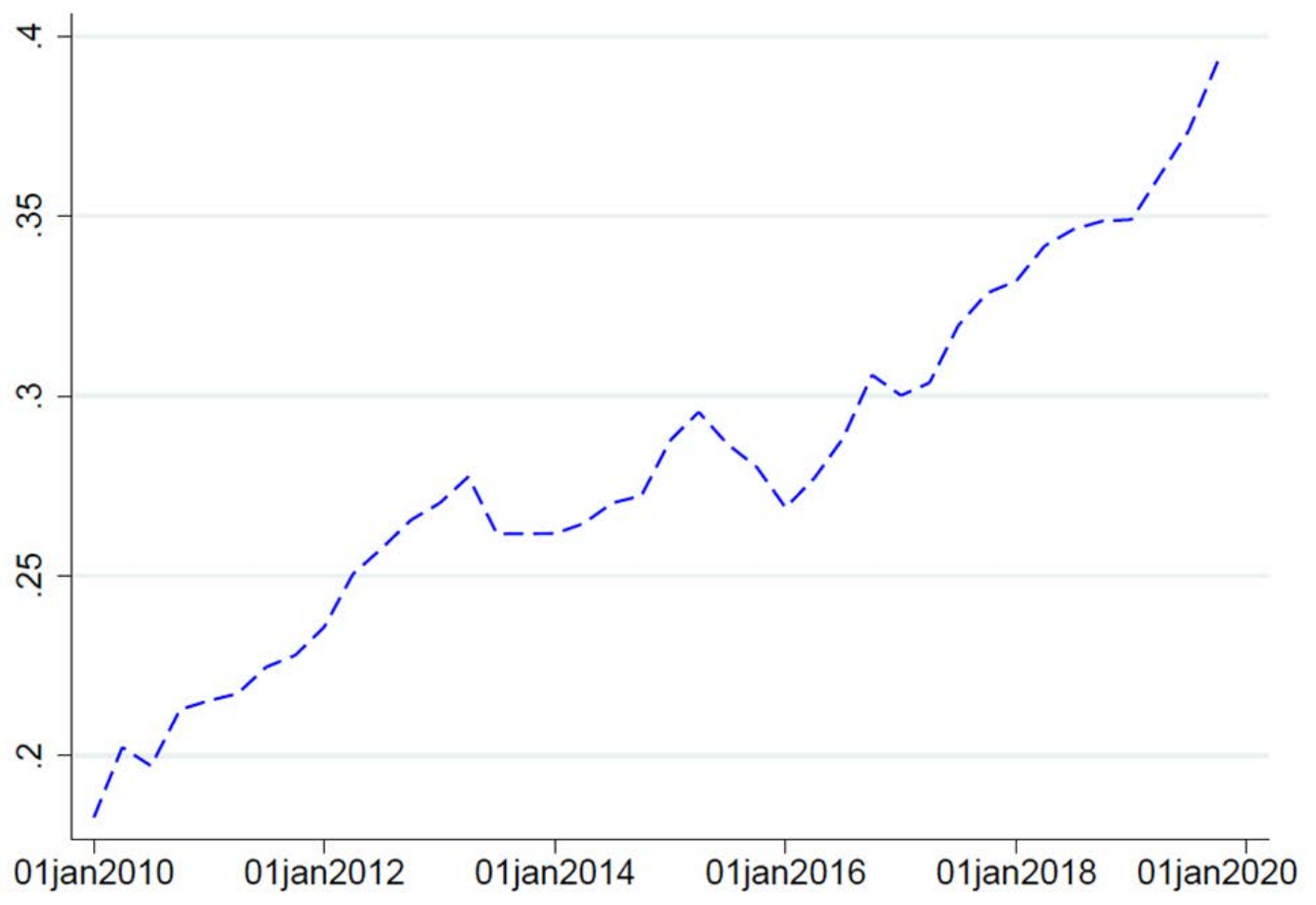


Figure 2: Fund Fragility in the COVID-19 Crisis

This figure plots the monthly (Panel A) and daily (Panel B) time-series of aggregate net flows of corporate bond funds as a percentage of their aggregate net assets. The numerator is the aggregate dollar growth of new assets of bond funds, which is calculated by aggregating over individual funds' growth of new assets. The denominator is the aggregate dollar value of their net assets at the beginning of each period (month in Panel A and day in Panel B), which is calculated by aggregating over individual funds' net assets. Time period is January 2010 to April 2020 in Panel A and January 2020 to April 2020 in Panel B.. Data Source: Morningstar.

Panel A: Long Term Perspective on Fund Fragility, Monthly Aggregate Net Fund Flows

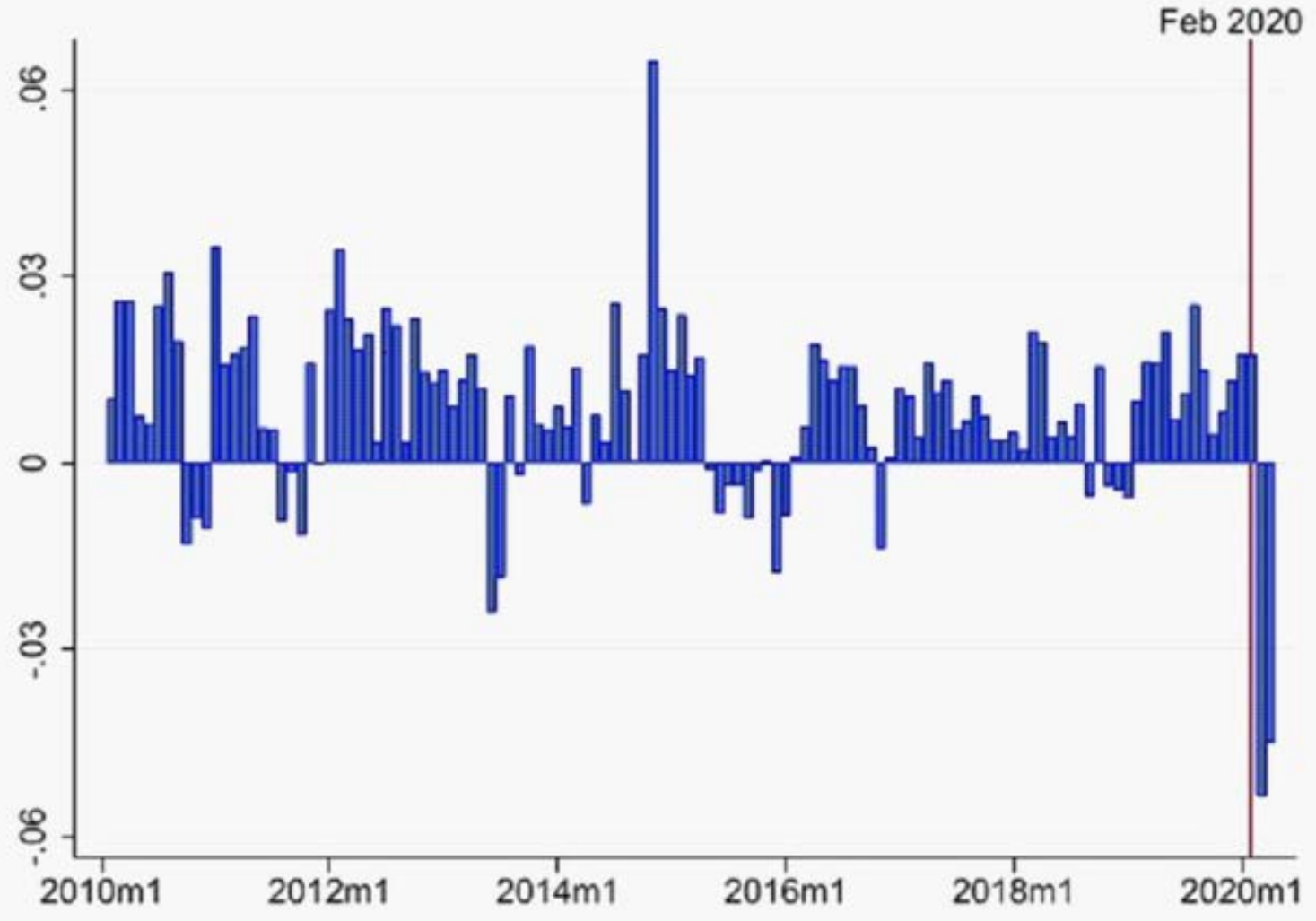


Panel B: Evolution of Flows over the Crisis, Daily Aggregate Net Fund Flows

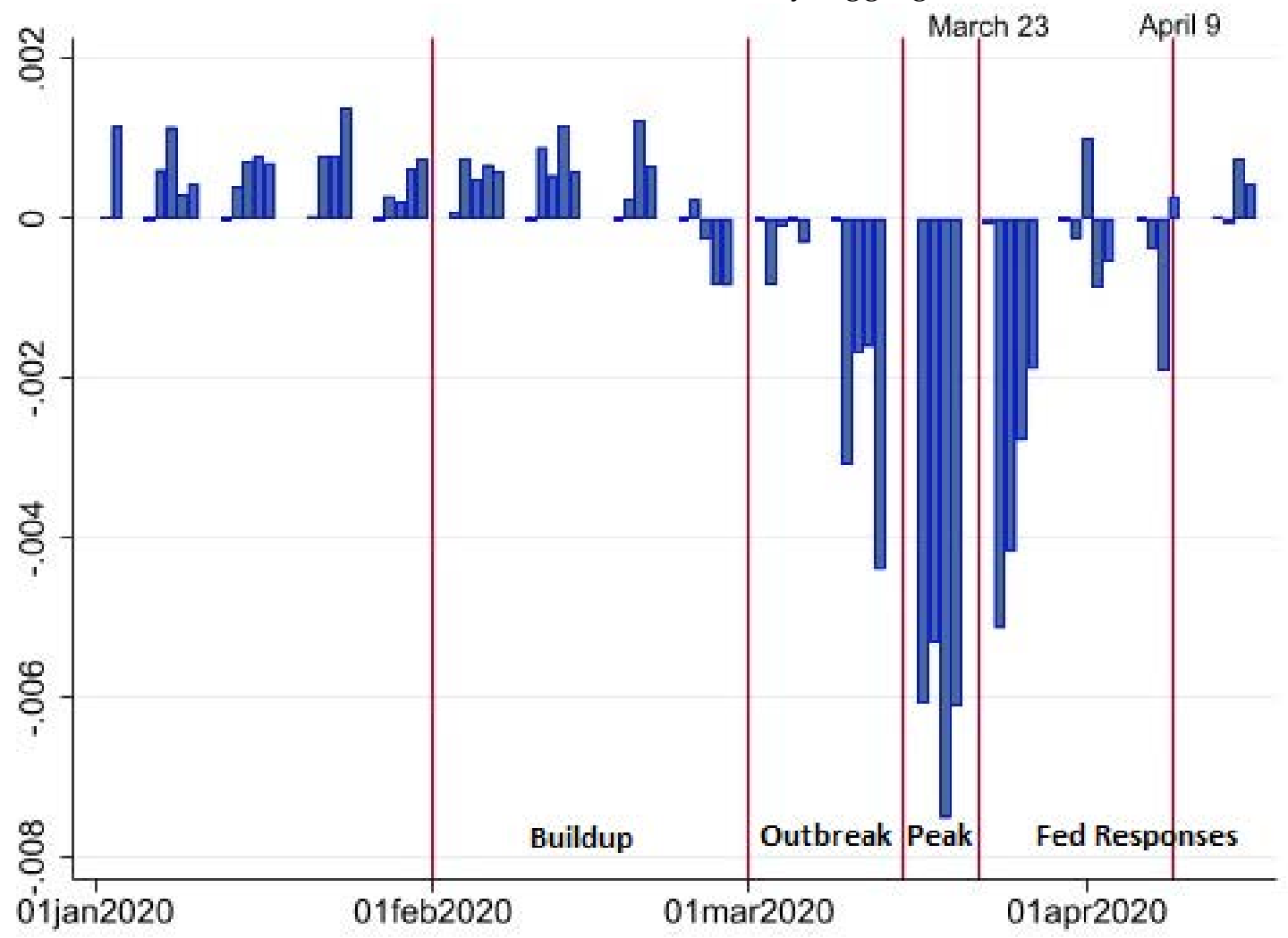


Appendix Table A.1: Sizing Up Fragility in the COVID-19 Crisis: Additional Analysis

This table reports additional share class-level regressions of daily flows on an indicator variable for the COVID-19 crisis (Panels A) and indicator variables for different stages of the crisis and policy response (Panel B). Panels A-B repeat the baseline analysis of Table 2 (Panels A-B) for the full sample that includes ETFs. Panel $\mathrm{C}$ repeats the analysis of Panel A for the crisis and post-crisis period (second half of April to August 2020). The time period is 2019-2020. All specifications include controls for fund size and month. Standard errors (in parentheses) are clustered by share class, with ${ }^{* * *},{ }^{* *}$, and ${ }^{*}$ denoting significance at the $1 \%, 5 \%$, and $10 \%$ level, respectively. Variable and specification details are in Appendix A-B.

\begin{tabular}{|c|c|c|c|c|}
\hline \multicolumn{5}{|c|}{ Panel A: Crisis Including ETFs } \\
\hline & Flows (\%) & Flows (\%) & Flows (\%) & Large \\
\hline & OLS & $\mathrm{FE}$ & Bottom Decile & Outflows \\
\hline & (1) & (2) & (3) & $(4)$ \\
\hline Crisis & $-0.25^{* * *}$ & $-0.30^{* * *}$ & $-1.47^{* * *}$ & $0.10^{* * *}$ \\
\hline & $(0.02)$ & $(0.02)$ & $(0.01)$ & $(0.00)$ \\
\hline FE & Month & Month, Fund & Month & Month \\
\hline Nobs & 717,440 & 717,440 & 717,440 & 717,440 \\
\hline $\mathrm{R}^{2}(\%)$ & 0.6 & 12.6 & 3.0 & 2.6 \\
\hline \multicolumn{5}{|c|}{ Panel B: Evolution of the Crisis and Policy Response Including ETFs } \\
\hline & Flows (\%) & Flows (\%) & Flows (\%) & Large \\
\hline & OLS & $\mathrm{FE}$ & Bottom Decile & Outflows \\
\hline & $(1)$ & (2) & (3) & $(4)$ \\
\hline \multirow[t]{2}{*}{ Peak (Mar 13-23, 2020) } & $-0.95^{* * *}$ & $-0.99^{* * *}$ & $-3.37^{* * *}$ & $0.29^{* * *}$ \\
\hline & $(0.05)$ & $(0.05)$ & $(0.05)$ & $(0.01)$ \\
\hline \multirow[t]{2}{*}{ First Response (Mar 23-Apr 9, 2020) } & $-0.52^{* * *}$ & $-0.56^{* * *}$ & $-1.99^{* * *}$ & $0.17^{* * *}$ \\
\hline & $(0.03)$ & $(0.03)$ & $(0.04)$ & $(0.00)$ \\
\hline \multirow{2}{*}{ Second Response (Apr 9-17, 2020) } & -0.02 & -0.07 & $-0.61^{* * *}$ & $0.08^{* * *}$ \\
\hline & $(0.04)$ & $(0.04)$ & $(0.03)$ & $(0.01)$ \\
\hline FE & Month & Month, Fund & Month & Month \\
\hline N obs & 717,440 & 717,440 & 717,440 & 717,440 \\
\hline $\mathrm{R}^{2}(\%)$ & 1.2 & 13.9 & 5.0 & 3.5 \\
\hline \multicolumn{5}{|c|}{ Panel C: Fund Flows Through August 2020} \\
\hline & Flows (\%) & Large & 2-Day Large & 2+SC Large \\
\hline & FE & Outflows & Outflows & Outflows \\
\hline & (1) & $(2)$ & (3) & $(4)$ \\
\hline \multirow[t]{2}{*}{ Feb-August 2020} & $-0.05^{* * *}$ & $0.05^{* * *}$ & $0.04^{* * *}$ & $0.05^{* * *}$ \\
\hline & $(0.01)$ & $(0.00)$ & $(0.00)$ & $(0.00)$ \\
\hline FE & Month, Fund & Month, Fund & Month, Fund & Month, Fund \\
\hline $\mathrm{N}$ obs & 913,097 & 913,097 & 913,097 & 913,097 \\
\hline $\mathrm{R}^{2}(\%)$ & 12.4 & 10.0 & 8.8 & 20.6 \\
\hline
\end{tabular}


Appendix Table A.2: Sizing Up Fragility in the COVID-19 Crisis: Robustness Analysis

This table reports share class-level regressions of daily flows on an indicator variable for the COVID-19 crisis (Panel A) and indicator variables for different stages of the crisis and policy response (Panel B) and additional regressions of daily persistent and daily correlated large outflows (Panel C). The time period is 2019-2020. All specifications include controls for fund size and month. Standard errors (in parentheses) are clustered by fund, with ${ }^{* * *}, * *$, and * denoting significance at the $1 \%, 5 \%$, and $10 \%$ level, respectively. Variable and specification details are in Appendix A-B.

\begin{tabular}{|c|c|c|c|c|}
\hline \multicolumn{5}{|c|}{ Panel A: Crisis } \\
\hline & Flows (\%) & Flows (\%) & Flows (\%) & Large \\
\hline & OLS & FE & Bottom Decile & Outflows \\
\hline & (1) & (2) & (3) & (4) \\
\hline Crisis (Feb-April 2020) & $\begin{array}{c}-0.25^{* * *} \\
(0.02)\end{array}$ & $\begin{array}{c}-0.29^{* * *} \\
(0.02)\end{array}$ & $\begin{array}{c}-1.39^{* * *} \\
(0.02)\end{array}$ & $\begin{array}{c}0.11^{* * *} \\
(0.00)\end{array}$ \\
\hline $\mathrm{FE}$ & Month & Month, Fund & Month & Month \\
\hline Nobs & 619,222 & 619,222 & 619,222 & 619,222 \\
\hline $\mathrm{R}^{2}(\%)$ & 0.8 & 13.9 & 3.1 & 2.6 \\
\hline \multicolumn{5}{|c|}{ Panel B: Evolution of the Crisis and Policy Response } \\
\hline & Flows (\%) & Flows (\%) & Flows (\%) & Large \\
\hline & OLS & FE & Bottom Decile & Outflows \\
\hline & $(1)$ & (2) & (3) & $(4)$ \\
\hline \multirow[t]{2}{*}{ Peak (Mar 13-23, 2020) } & $-0.89^{* * *}$ & $-0.92^{* * *}$ & $-3.16^{* * *}$ & $0.29^{* * *}$ \\
\hline & $(0.07)$ & $(0.07)$ & $(0.07)$ & $(0.01)$ \\
\hline \multirow[t]{2}{*}{ First Response (Mar 23-Apr 9, 2020) } & $-0.52^{* * *}$ & $-0.55^{* * *}$ & $-1.97^{* * *}$ & $0.18^{* * *}$ \\
\hline & $(0.04)$ & $(0.04)$ & $(0.03)$ & $(0.01)$ \\
\hline \multirow[t]{2}{*}{ Second Response (Apr 9-17, 2020) } & $-0.08^{*}$ & $-0.11^{* *}$ & $-0.62^{* * *}$ & $0.09^{* * *}$ \\
\hline & $(0.06)$ & $(0.06)$ & $(0.07)$ & $(0.01)$ \\
\hline FE & Month & Month, Fund & Month & Month \\
\hline $\mathrm{N}$ obs & 619,222 & 619,222 & 619,222 & 619,222 \\
\hline \multirow[t]{5}{*}{$\mathrm{R}^{2}(\%)$} & 1.2 & 14.0 & 4.7 & 3.5 \\
\hline & ditional Analy & s of Large Outfl & WWs & \\
\hline & 2-day Large & 3-day Large & 2+SC Large & 3+SC Large \\
\hline & Outflows & Outflows & Outflows & Outflows \\
\hline & (1) & (2) & (3) & (4) \\
\hline \multirow[t]{2}{*}{ Peak (Mar 13-23, 2020) } & $0.22^{* * *}$ & $0.15^{* * *}$ & $0.38^{* * *}$ & $0.28^{* * *}$ \\
\hline & $(0.01)$ & $(0.01)$ & $(0.02)$ & $(0.02)$ \\
\hline \multirow[t]{2}{*}{ First Response (Mar 23-Apr 9, 2020) } & $0.15^{* * *}$ & $0.09^{* * *}$ & $0.25^{* * *}$ & $0.18^{* * *}$ \\
\hline & $(0.01)$ & $(0.00)$ & $(0.01)$ & $(0.01)$ \\
\hline \multirow[t]{2}{*}{ Second Response (Apr 9-17, 2020) } & $0.08^{* * *}$ & $0.04^{* * *}$ & $0.15^{* * *}$ & $0.08^{* * *}$ \\
\hline & $(0.01)$ & $(0.00)$ & $(0.02)$ & $(0.01)$ \\
\hline $\mathrm{FE}$ & Month & Month & Month & Month \\
\hline Nobs & 619,222 & 619,222 & 619,222 & 619,222 \\
\hline $\mathrm{R}^{2}(\%)$ & 3.2 & 2.4 & 5.5 & 7.2 \\
\hline
\end{tabular}


Appendix Table A.3: Sizing Up Fragility in the COVID-19 Crisis: Additional Estimates on the Evolution of the Crisis

This table reports additional coefficient estimates for the share class-level regressions of daily flows on indicator variables for different stages of the COVID-19 crisis and policy response (Table 2, Panels B-C) The time period is 2019-2020. All specifications include controls for fund size and month. Standard errors (in parentheses) are clustered by share class, with ${ }^{* *},{ }^{* *}$, and ${ }^{*}$ denoting significance at the $1 \%, 5 \%$, and $10 \%$ level, respectively. Variable and specification details are in Appendix A-B.

\begin{tabular}{|c|c|c|c|c|}
\hline \multicolumn{5}{|c|}{ Panel A: Analysis of Fund Flows } \\
\hline & $\begin{array}{c}\text { Flows (\%) } \\
\text { OLS } \\
(1)\end{array}$ & $\begin{array}{c}\text { Flows (\%) } \\
\text { FE } \\
(2)\end{array}$ & $\begin{array}{c}\text { Flows (\%) } \\
\text { Bottom Decile } \\
\text { (3) }\end{array}$ & $\begin{array}{c}\text { Large } \\
\text { Outflows } \\
(4)\end{array}$ \\
\hline Buildup (Feb 2020) & $\begin{array}{l}0.07^{* *} \\
(0.03)\end{array}$ & $\begin{array}{c}0.03 \\
(0.02)\end{array}$ & $\begin{array}{c}0.07^{* * *} \\
(0.01)\end{array}$ & $\begin{array}{c}-0.01^{* *} \\
(0.00)\end{array}$ \\
\hline Outbreak (Mar 1-13, 2020) & $\begin{array}{c}0.04 \\
(0.04)\end{array}$ & $\begin{array}{c}0.00 \\
(0.03)\end{array}$ & $\begin{array}{c}-1.36^{* * *} \\
(0.04)\end{array}$ & $\begin{array}{c}0.07^{* * *} \\
(0.01)\end{array}$ \\
\hline Peak (Mar 13-23, 2020) & $\begin{array}{c}-0.89^{* * *} \\
(0.05)\end{array}$ & $\begin{array}{c}-0.92^{* * *} \\
(0.05)\end{array}$ & $\begin{array}{c}-3.16^{* * *} \\
(0.07)\end{array}$ & $\begin{array}{c}0.29^{* * *} \\
(0.01)\end{array}$ \\
\hline $\begin{array}{l}\mathrm{FE} \\
\mathrm{N} \text { obs }\end{array}$ & $\begin{array}{l}\text { Month } \\
619,222\end{array}$ & $\begin{array}{c}\text { Month, Fund } \\
619,222\end{array}$ & $\begin{array}{l}\text { Month } \\
619,222\end{array}$ & $\begin{array}{l}\text { Month } \\
619,222\end{array}$ \\
\hline $\mathrm{R}^{2}(\%)$ & 1.2 & 14.0 & 4.7 & 3.5 \\
\hline \multicolumn{5}{|c|}{ Panel B: Additional Analysis of Large Outflows } \\
\hline & $\begin{array}{c}\text { 2-day Large } \\
\text { Outflows } \\
\text { (1) }\end{array}$ & $\begin{array}{l}\text { 3-day Large } \\
\text { Outflows } \\
\text { (2) }\end{array}$ & $\begin{array}{c}2+\text { SC Large } \\
\text { Outflows } \\
\text { (3) }\end{array}$ & $\begin{array}{c}\text { 3+SC Large } \\
\text { Outflows } \\
(4)\end{array}$ \\
\hline Buildup (Feb 2020) & $\begin{array}{c}-0.01^{* * *} \\
(0.00)\end{array}$ & $\begin{array}{c}-0.01^{* * *} \\
(0.00)\end{array}$ & $\begin{array}{c}-0.01^{* * *} \\
(0.00)\end{array}$ & $\begin{array}{c}-0.01^{* *} \\
(0.00)\end{array}$ \\
\hline Outbreak (Mar 1-13, 2020) & $\begin{array}{c}0.05^{* * *} \\
(0.00)\end{array}$ & $\begin{array}{c}0.04^{* * *} \\
(0.00)\end{array}$ & $\begin{array}{c}0.10^{* * *} \\
(0.01)\end{array}$ & $\begin{array}{c}0.04^{* * *} \\
(0.00)\end{array}$ \\
\hline Peak (Mar 13-23, 2020) & $\begin{array}{c}0.22^{* * * *} \\
(0.01)\end{array}$ & $\begin{array}{c}0.15^{* * *} \\
(0.01)\end{array}$ & $\begin{array}{c}0.38^{* * *} \\
(0.01)\end{array}$ & $\begin{array}{c}0.28^{* * *} \\
(0.01)\end{array}$ \\
\hline FE & Month & Month & Month & Month \\
\hline $\mathrm{N}$ obs & 619,222 & 619,222 & 619,222 & 619,222 \\
\hline $\mathrm{R}^{2}(\%)$ & 3.2 & 2.4 & 5.5 & 7.2 \\
\hline
\end{tabular}


Appendix Table A.4: Heterogeneity Analysis of the Sources of Fragility: Additional Estimates on the Evolution of the Crisis

This table reports additional coefficient estimates for the sample split analysis of daily flows regressed on indicator variables for different stages of the COVID-19 crisis and policy response (Table 3, Panels B-C). In Panel A, sample splits are by fund liquidity based on Roll (Columns 1-2), bid-ask spreads (Columns 3-4), and bond ratings (Columns 5-6). In Panel B, sample splits are by fund vulnerability to fire-sale spillovers (Columns 1-2), age (Columns 3-4), and maturity (Columns 5-6). The time period is 2019-2020. All specifications include controls for fund size and month. Standard errors (in parentheses) are clustered by share class, with ***,**, and ${ }^{*}$ denoting significance at the $1 \%, 5 \%$, and $10 \%$ level, respectively. Variable and specification details are in Appendix A-B.

\begin{tabular}{|c|c|c|c|c|c|c|}
\hline \multicolumn{7}{|c|}{ Panel A: Evolution of the Crisis by Fund Liquidity } \\
\hline & \multicolumn{2}{|c|}{ Roll } & \multicolumn{2}{|c|}{ Bid-Ask } & \multicolumn{2}{|c|}{ Ratings } \\
\hline & Illiq & Liq & Illiq & Liq & Illiq & Liq \\
\hline & (1) & (2) & (3) & (4) & (5) & (6) \\
\hline Buildup (Feb 2020) & $\begin{array}{l}-0.03 \\
(0.07)\end{array}$ & $\begin{array}{c}0.25^{* * *} \\
(0.06)\end{array}$ & $\begin{array}{l}-0.07 \\
(0.06)\end{array}$ & $\begin{array}{c}0.27^{* * *} \\
(0.06)\end{array}$ & $\begin{array}{c}-0.15^{* *} \\
(0.06)\end{array}$ & $\begin{array}{c}0.20^{* * * *} \\
(0.06)\end{array}$ \\
\hline Outbreak (Mar 1-13, 2020) & $-0.27^{* * *}$ & $0.34^{* * *}$ & $-0.31^{* * *}$ & $0.43^{* * *}$ & $-0.68^{* * * *}$ & $0.54^{* * *}$ \\
\hline Peak (Mar 13-23, 2020) & $\begin{array}{c}-1.28^{* * *} \\
(0.10)\end{array}$ & $\begin{array}{c}-0.67^{* * *} \\
(0.16)\end{array}$ & $\begin{array}{c}-1.35^{* * *} \\
(0.11)\end{array}$ & $\begin{array}{c}-0.45^{* * *} \\
(0.15)\end{array}$ & $\begin{array}{c}-1.72^{* * *} \\
(0.10)\end{array}$ & $\begin{array}{l}-0.02 \\
(0.16)\end{array}$ \\
\hline Month, Fund FE & Yes & Yes & Yes & Yes & Yes & Yes \\
\hline Nobs & 86,954 & 87,134 & 88,600 & 86,599 & 100,923 & 86,795 \\
\hline $\mathrm{R}^{2}(\%)$ & 14.2 & 8.6 & 12.4 & 7.4 & 14.3 & 8.0 \\
\hline \multicolumn{7}{|c|}{ Panel B: Evolution of the Crisis by Fund Fire-Sale Spillovers, Age, \& Maturity } \\
\hline & \multicolumn{2}{|c|}{ Vulnerability } & \multicolumn{2}{|c|}{ Age } & \multicolumn{2}{|c|}{ Maturity } \\
\hline & Low & High & Young & Old & Short & Long \\
\hline & (1) & (2) & (3) & (4) & (5) & (6) \\
\hline Buildup (Feb 2020) & $\begin{array}{c}0.10^{* * *} \\
(0.03)\end{array}$ & $\begin{array}{l}-0.02 \\
(0.04)\end{array}$ & $\begin{array}{l}-0.05 \\
(0.06)\end{array}$ & $\begin{array}{c}0.08^{* *} \\
(0.03)\end{array}$ & $\begin{array}{c}0.25^{* *} \\
(0.10)\end{array}$ & $\begin{array}{c}0.13 \\
(0.10)\end{array}$ \\
\hline Outbreak (Mar 1-13, 2020) & $\begin{array}{c}0.03 \\
(0.03)\end{array}$ & $\begin{array}{l}-0.01 \\
(0.05)\end{array}$ & $\begin{array}{l}-0.06 \\
(0.07)\end{array}$ & $\begin{array}{c}0.21^{* * *} \\
(0.06)\end{array}$ & $\begin{array}{c}0.59^{* * *} \\
(0.17)\end{array}$ & $\begin{array}{c}0.21 \\
(0.14)\end{array}$ \\
\hline Peak (Mar 13-23, 2020) & $\begin{array}{c}-0.65^{* * *} \\
(0.06)\end{array}$ & $\begin{array}{c}-1.09^{* * *} \\
(0.08)\end{array}$ & $\begin{array}{c}-0.79^{* * *} \\
(0.11)\end{array}$ & $\begin{array}{c}-0.64^{* * *} \\
(0.07)\end{array}$ & $\begin{array}{c}-0.56^{* *} \\
(0.23)\end{array}$ & $\begin{array}{c}-0.75^{* * *} \\
(0.16)\end{array}$ \\
\hline Month, Fund FE & Yes & Yes & Yes & Yes & Yes & Yes \\
\hline $\mathrm{N}$ obs & 165,403 & 177,561 & 169,086 & 182,969 & 32,973 & 33,710 \\
\hline $\mathrm{R}^{2}(\%)$ & 13.6 & 13.9 & 15.1 & 9.7 & 6.4 & 10.3 \\
\hline
\end{tabular}


Appendix Table A.5: Sources of Fragility in the COVID-19 Crisis: Analysis of the Flow-Performance Relation

This table reports share class-level regressions of daily flows on daily performance and its interaction with an indicator variable for the COVID-19 crisis. The time period is 2019-2020. All specifications include controls for fund size and month. Standard errors (in parentheses) are clustered by share class, with ***,**, and ${ }^{*}$ denoting significance at the $1 \%, 5 \%$, and $10 \%$ level, respectively. Variable and specification details are in Appendix A-B.

\begin{tabular}{|c|c|c|c|c|}
\hline \multicolumn{5}{|c|}{ Panel A: Analysis of the Flow-Performance Relation } \\
\hline & Flows (\%) & Flows (\%) & Flows (\%) & Flows (\%) \\
\hline & FE & FE, lag dep & $\mathrm{FE}$ & FE, lag dep \\
\hline & (1) & (2) & (3) & (4) \\
\hline \multirow{2}{*}{ Crisis (Feb-April 2020) } & $-0.29^{* * *}$ & $-0.20^{* * *}$ & $-0.06^{* *}$ & $-0.04^{* *}$ \\
\hline & $(0.02)$ & $(0.02)$ & $(0.03)$ & $(0.02)$ \\
\hline \multirow{2}{*}{ Return } & $1.95^{* * *}$ & $2.38^{* * *}$ & & \\
\hline & $(0.83)$ & $(0.81)$ & & \\
\hline \multirow[t]{2}{*}{ Crisis* Return } & $17.17^{* * *}$ & $15.19^{* * *}$ & & \\
\hline & $(1.12)$ & $(1.00)$ & & \\
\hline \multirow[t]{2}{*}{ Return $^{-}$} & & & 1.53 & -2.10 \\
\hline & & & $(1.23)$ & $(2.14)$ \\
\hline \multirow[t]{2}{*}{ Return $^{+}$} & & & $4.51^{* * *}$ & $5.75^{* * *}$ \\
\hline & & & $(1.31)$ & $(1.24)$ \\
\hline \multirow[t]{2}{*}{ Crisis $^{*}$ Return $^{-}$} & & & $36.48^{* * *}$ & $29.97^{* * *}$ \\
\hline & & & $(1.89)$ & $(1.62)$ \\
\hline \multirow[t]{2}{*}{ Crisis $^{*}$ Return ${ }^{+}$} & & & $-6.88^{* * *}$ & -2.12 \\
\hline & & & $(2.04)$ & (1.77) \\
\hline FE & Month, Fund & Month, Fund & Month, Fund & Month, Fund \\
\hline $\mathrm{N}$ obs & 619,222 & 619,222 & 619,222 & 619,222 \\
\hline $\mathrm{R}^{2}(\%)$ & 14.4 & 22.9 & 14.6 & 23.0 \\
\hline
\end{tabular}




\section{Appendix Table A.6: Analysis of ETFs: Additional Estimates on the Evolution of the Crisis}

This table shows additional additional coefficient estimates for the matched-sample analysis of ETF flows. Panel A shows results for indicator variables for different stages of the COVID-19 crisis and policy response (Table 4, Panel B). To implement the estimator, we use a methodology analogous to long-run event studies and for each ETF-day construct a "benchmark" flow variable, $\overline{F l o w s}_{-i, t}$, for a matched portfolio of bond funds. The covariates used for matching are size, age, and performance. We then repeat the baseline analysis for Flows $s_{i, t}-\overline{\text { Flows }}_{-i, t}$. The time period is 2019-2020. All specifications include controls for fund size and month. Standard errors (in parentheses) are clustered by share class, with ${ }^{* *},{ }^{* *}$, and * denoting significance at the $1 \%, 5 \%$, and $10 \%$ level, respectively. Variable and specification details are in Appendix A-B.

\begin{tabular}{lcccc}
\hline \multicolumn{5}{c}{ Panel A: Evolution of the Crisis and Policy Response } \\
& Flows (\%) & Large & 2-Day Large & 2+SC Large \\
& FE & Outflows & Outflows & Outflows \\
& $(1)$ & $(2)$ & $(3)$ & $(4)$ \\
Buildup (Feb 2020) & 0.02 & -0.01 & -0.00 & 0.00 \\
& $(0.08)$ & $(0.01)$ & $(0.01)$ & $(0.00)$ \\
Outbreak (Mar 1-13, 2020) & 0.12 & $-0.04^{* * *}$ & $-0.04^{* * *}$ & $-0.10^{* * *}$ \\
& $(0.09)$ & $(0.01)$ & $(0.01)$ & $(0.00)$ \\
Peak (Mar 13-23, 2020) & -0.10 & $-0.06^{* * *}$ & $-0.04^{* * *}$ & $-0.27^{* * *}$ \\
& $(0.13)$ & $(0.02)$ & $(0.02)$ & $(0.00)$ \\
FE & & & & \\
$\mathrm{N}$ obs & Month, Fund & Month, Fund & Month, Fund & Month, Fund \\
$\mathrm{R}^{2}(\%)$ & 93,654 & 93,654 & 93,654 & 93,654 \\
\hline & 9.9 & 10.1 & 6.5 & 35.9 \\
\hline
\end{tabular}


Appendix Table A.7: Analysis by Fund Sector Exposure: Additional Estimates on the Evolution of the Crisis

This table reports additional coefficient estimates for the share class-level regressions of daily flows on an indicator for fund COVID-19 sector exposure and its interaction with an indicator for different stages of the COVID-19 crisis and policy response (Table 5, Columns 3-4). The COVID-19 sector exposure is based on holdings of the following Fama-French 49 industries: Entertainment, Construction, Automobiles and trucks, Aircraft, Ships, Personal services, Business services, Transportation, Wholesale, Retail, and Restaurants, hotels and motels. The time period is 2019-2020. All specifications include controls for fund size and month. Standard errors (in parentheses) are clustered by share class, with ${ }^{* * *}, * *$, and * denoting significance at the $1 \%, 5 \%$, and $10 \%$ level, respectively. Variable and specification details are in Appendix A-B.

\begin{tabular}{lcc}
\hline \multicolumn{3}{c}{ Panel A: Analysis by Fund Sector Exposure } \\
\hline \multicolumn{4}{c}{ Crisis and Policy Response } \\
& OLS & FE \\
Buildup (Feb 2020) & $(1)$ & $(2)$ \\
& $0.17^{* * *}$ & $0.13^{* * *}$ \\
Outbreak (Mar 1-13, 2020) & $(0.05)$ & $(0.05)$ \\
& $0.24^{* * *}$ & $0.20^{* * *}$ \\
Peak (Mar 13-23, 2020) & $(0.08)$ & $(0.07)$ \\
& $-0.78^{* * *}$ & $-0.81^{* * *}$ \\
& $(0.12)$ & $(0.12)$ \\
High Exposure Fund & & \\
& -0.01 & \\
High Exposure Fund ${ }^{*}$ Buildup & $(0.03)$ & \\
High Exposure Fund ${ }^{*}$ Outbreak & $-0.18^{* * *}$ & $-0.16^{* * *}$ \\
& $(0.05)$ & $(0.05)$ \\
High Exposure Fund*Peak & $-0.69^{* * *}$ & $-0.65^{* * *}$ \\
& $(0.11)$ & $(0.11)$ \\
Month FE & $-0.76^{* * *}$ & $-0.71^{* * *}$ \\
Fund FE & $(0.18)$ & $(0.18)$ \\
N obs & & \\
$\mathrm{R}^{2}(\%)$ & Yes & Yes \\
\end{tabular}


Appendix Table A.8: Sources of Fragility in the COVID-19 Crisis: Additional Analysis of Cumulative Flows

This table reports robustness results of the sample splits analysis of cumulative flows in Table 8. In Panel A, we repeat the univariate sorts based on fund illiquidity, fire-sale vulnerability and COVID-sector exposure for the sub-sample of investment grade funds. In Panel B, for each source of fragility (illiquidity, firesale vulnerability and COVID-sector exposure), we first run a regression on the other sources and then use the estimated residual to split the sample. For example, take illiquidity. We first run a regression of the illiquidity proxy (Roll) on fire-sale vulnerability and sector exposure and then split the sample into two subsamples based on top vs. bottom quartiles of the estimated residual. Variable definitions are in Appendix A.

\begin{tabular}{lcc}
\hline \hline \multicolumn{3}{c}{ Panel A: Cumulative Flows in the Crisis - Investment Grade (IG) Funds Only } \\
\hline & Feb-Mar, 2020 & Mar-Apr, 2020 \\
& $(1)$ & $(2)$ \\
Cumulative Flows, IG Funds & $-3.2 \%$ & $-1.2 \%$ \\
Cumulative Flows, IG \& Illiquid Funds (Roll) & $-9.5 \%$ & $-7.2 \%$ \\
Cumulative Flows, IG \& Fire-Sale Vulnerable Funds & $-5.7 \%$ & $-2.3 \%$ \\
Cumulative Flows, IG \& High Sector Exposure Funds & $-6.6 \%$ & $-5.0 \%$ \\
\hline Panel B: Cumulative Flows in the Crisis - Orthogonalized Splits & \\
\hline & Feb-Mar, 2020 & \\
\hline & $-10.2 \%$ & $-6.7 \%$ \\
Cumulative Flows & $-19.9 \%$ & $-15.5 \%$ \\
Cumulative Flows, Illiquid Funds (Roll) & $-12.5 \%$ & $-8.5 \%$ \\
Cumulative Flows, Fire-Sale Vulnerable Funds & $-13.7 \%$ & $-11.7 \%$ \\
Cumulative Flows, High Sector Exposure Funds & &
\end{tabular}




\section{Appendix Table A.9: The Fragility Channel of SMCCF: Additional Analysis}

This table reports additional regressions of cumulative fund flows on measures of fund exposure to the SMCCF purchase eligibility. We expand on the sample split analysis of Table 7 (Panel A) by adding results for the low illiquidity and vulnerability sub-samples. Panel A reports results for cumulative percentage flows in the post-SMCCF period from April 10 through August 31, 2020, and Panel B reports results for large outflows. The SMCCF Share is a fund-level weighted sum of dummies for whether a given bond was eligible to be purchased by the SMCCF, with weights calculated based on the asset allocation of a given fund (percentage portfolio share holdings of each eligible security as of February 2020). The eligibility criteria are from the term sheet of the SMCCF. All specifications include controls for fund size. To ease interpretation, the explanatory variables are expressed in standard deviation units. Standard errors are in parentheses, with $* * * * *$, and $*$ denoting significance at the $1 \%, 5 \%$, and $10 \%$ level, respectively. Variable definitions are in Appendix A.

\begin{tabular}{|c|c|c|c|c|c|c|}
\hline \multicolumn{7}{|c|}{ Panel A: Fund Impact of Purchase Eligibility, Cumulative Flows (\%) } \\
\hline & \multicolumn{3}{|c|}{ Illiquidity } & \multicolumn{3}{|c|}{ Vulnerability } \\
\hline & $\begin{array}{l}\text { All } \\
(1)\end{array}$ & $\begin{array}{l}\text { High } \\
(2)\end{array}$ & $\begin{array}{l}\text { Low } \\
\text { (3) }\end{array}$ & $\begin{array}{l}\text { All } \\
(4)\end{array}$ & $\begin{array}{l}\text { High } \\
\text { (5) }\end{array}$ & $\begin{array}{l}\text { Low } \\
(6)\end{array}$ \\
\hline SMCCF Share $_{i}$ & $\begin{array}{c}2.76^{* * *} \\
(0.82)\end{array}$ & $\begin{array}{c}5.39^{* * *} \\
(1.16)\end{array}$ & $\begin{array}{c}0.03 \\
(2.64)\end{array}$ & $\begin{array}{c}2.76^{* * *} \\
(0.82)\end{array}$ & $\begin{array}{c}7.69^{* * *} \\
(2.69)\end{array}$ & $\begin{array}{c}-0.82 \\
(1.41)\end{array}$ \\
\hline Nobs. & 2,441 & 324 & 310 & 2,441 & 346 & 363 \\
\hline $\mathrm{R}^{2}(\%)$ & 0.70 & 1.87 & 0.19 & 0.70 & 2.45 & 0.10 \\
\hline \multicolumn{7}{|c|}{ Panel B: Fund Impact of Purchase Eligibility, Large Outflows } \\
\hline & \multicolumn{3}{|c|}{ Illiquidity } & \multicolumn{3}{|c|}{ Vulnerability } \\
\hline & $\begin{array}{l}\text { All } \\
(1)\end{array}$ & $\begin{array}{l}\text { High } \\
(2)\end{array}$ & $\begin{array}{l}\text { Low } \\
\text { (3) }\end{array}$ & $\begin{array}{l}\text { All } \\
(4)\end{array}$ & $\begin{array}{l}\text { High } \\
\text { (5) }\end{array}$ & $\begin{array}{l}\text { Low } \\
(6)\end{array}$ \\
\hline SMCCF Treated $_{i}$ & $\begin{array}{c}-0.02^{* * *} \\
(0.00)\end{array}$ & $\begin{array}{c}-0.02^{* * *} \\
(0.01)\end{array}$ & $\begin{array}{l}-0.01 \\
(0.01)\end{array}$ & $\begin{array}{c}-0.02^{* * *} \\
(0.00)\end{array}$ & $\begin{array}{c}-0.04^{* * *} \\
(0.01)\end{array}$ & $\begin{array}{l}-0.01^{*} \\
(0.01)\end{array}$ \\
\hline Nobs. & 2,441 & 324 & 310 & 2,441 & 346 & 363 \\
\hline $\mathrm{R}^{2}(\%)$ & 2.27 & 4.07 & 1.05 & 2.27 & 10.20 & 2.86 \\
\hline
\end{tabular}




\section{Appendix Figure A.1: Stress in the Corporate Bond Market}

This figure plots the daily time-series of spreads for investment-grade (Panel A) and high-yield (Panel B) rated nonfinancial corporate bonds. Spreads are defined as the difference between the respective corporate bond yields and those of comparable-maturity treasuries. Time period is January 1, 2020 to May 18, 2020. Data Source: ICE indices.

Panel A: Investment-Grade Bond Spreads

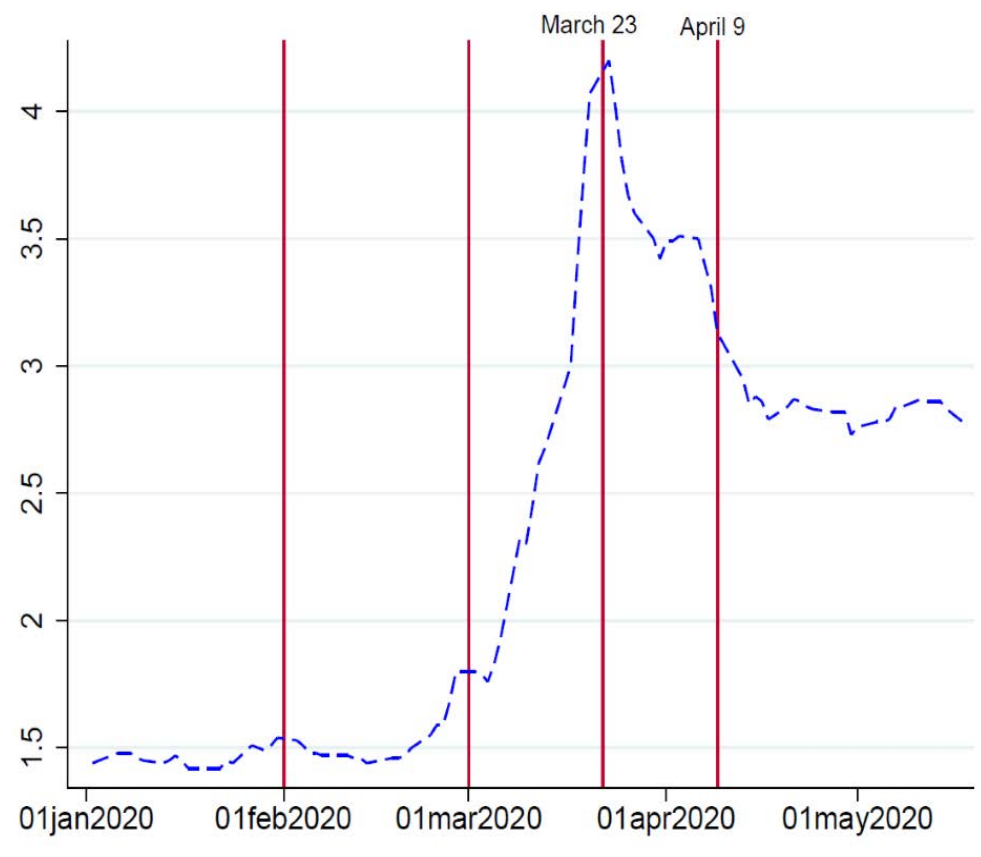

Panel B: High-Yield Bond Spreads

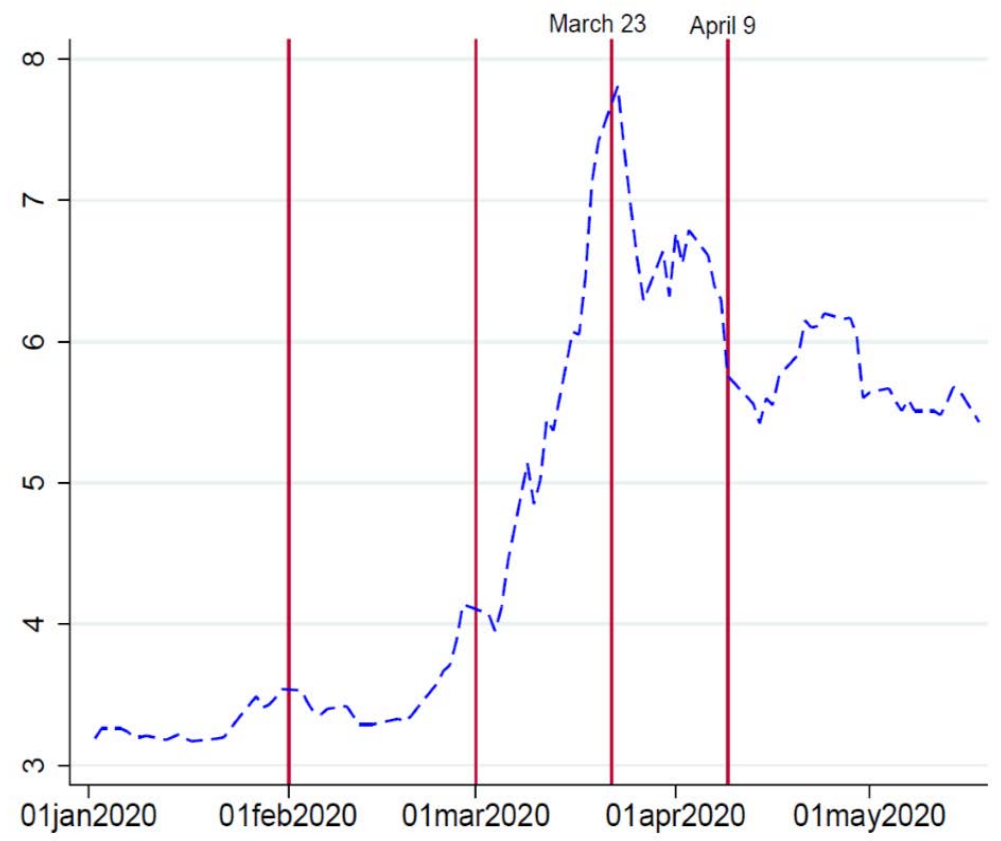


Appendix Figure A.2: Long Term Perspective on Fund Fragility, Additional Outcomes

This figure plots the daily time-series of the fraction of corporate bond funds that experience large outflows (Panel A) and large persistent outflows (Panel B). In each day, the net fraction is calculated as the number of funds that experience large outflows in a given day minus the number of funds that experience large inflows in a given day, divided by the total number of funds. Large outflows are defined as those in the bottom $10 \%$ of the unconditional distribution of individual funds' net fund flows relative to net assets, as it is standard in the literature (see, for example, Coval and Stafford, 2007). Large persistent outflows are defined as large outflows in two consecutive days. Positive (negative) values indicate net outflows (inflows). Time period is January 2010 to April 2020. Data Source: Morningstar.

Panel A: Daily Net Fraction of Funds with Large Outflows

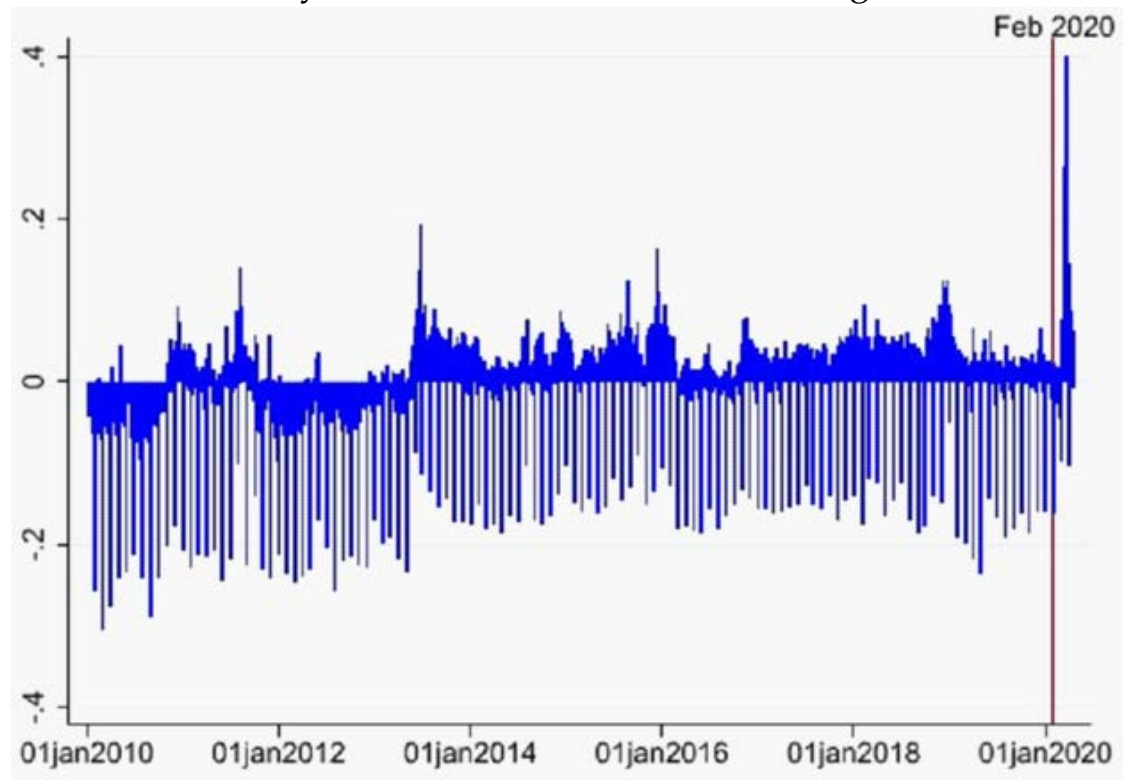

Panel B: Daily Net Fraction of Funds with Large Persistent Outflows

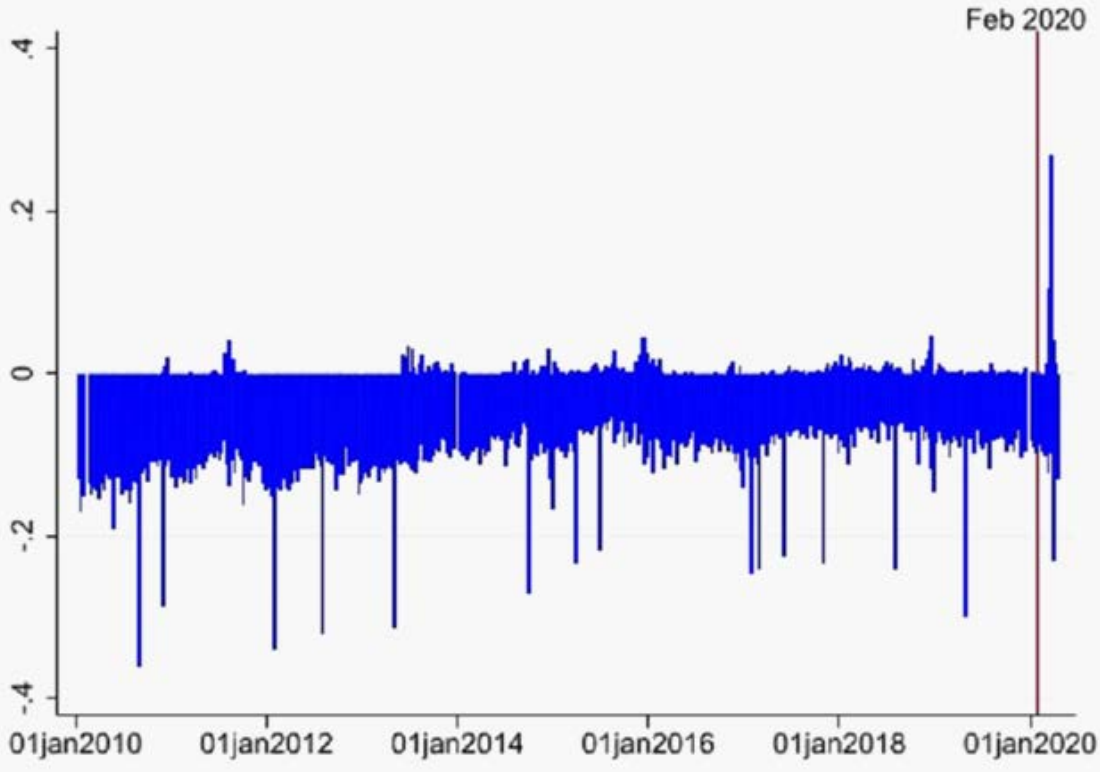


This figure plots the daily time-series of aggregate net flows as a percentage of aggregate net assets separately for investment-grade funds (Panel A), high-yield funds (Panel B), and ETFs (Panel C). The numerator is the aggregate dollar growth of new assets, which is calculated by aggregating over individual funds' growth of new assets. The denominator is the aggregate dollar value of their net assets at the beginning of each day, which is calculated by aggregating over individual funds' net assets. Time period is January 2020 to April 2020. Data Source: Morningstar.

\section{Panel A: Investment-Grade Funds}

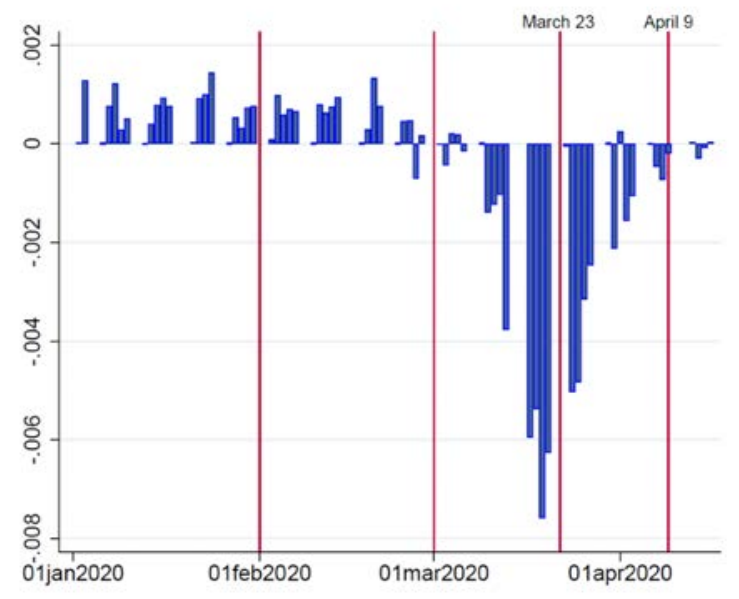

Panel B: High-Yield Funds

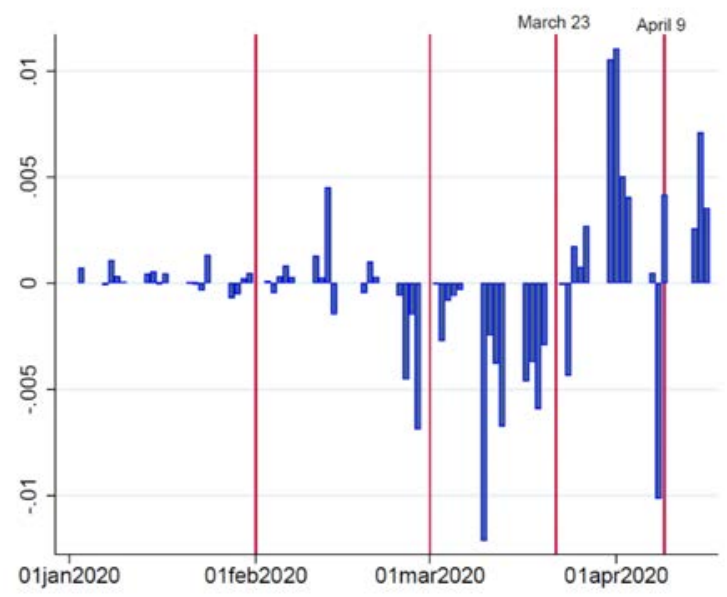


Panel C: ETFs

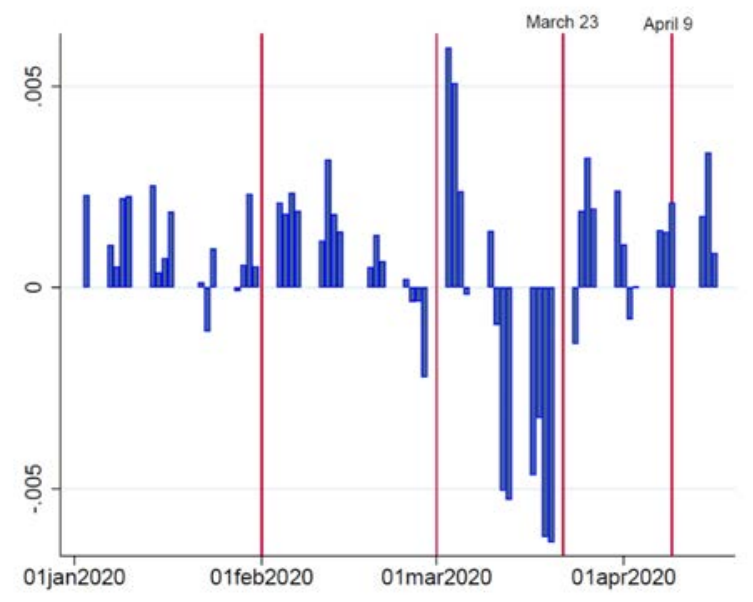


Appendix Figure A.4: Evolution of Flows over the Crisis, Cumulative Daily Net Fraction of Funds with Explosive Flows

This figure plots the cumulative daily time-series of the net fraction of corporate bond funds that experience explosive flows. Explosive flows are defined as those for which the fund flow process has a significant explosive unit root based on a recursive Augmented Dickey-Fuller (ADF) test procedure using an expanding window starting from January 1, 2020. This approach to measuring fund fragility is similar to tests of rational bubbles by Phillips, Shi, and Yu (2015). Time period is January 2020 to April 2020. Data Source: Morningstar.

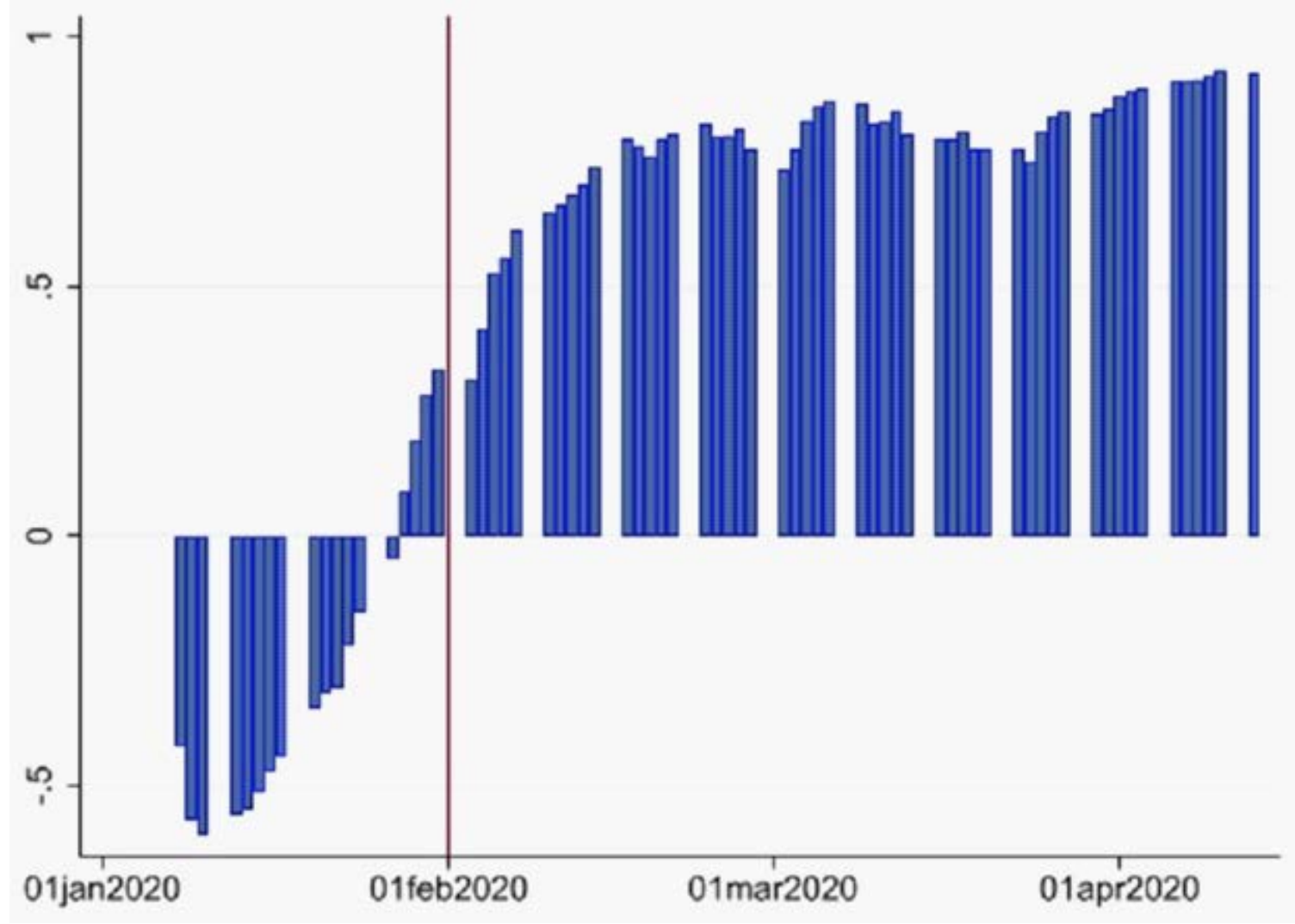

